\title{
Three-dimensional and two-phase numerical simulation of fractured dry gas reservoirs
}

\author{
Ahmadreza Ejraei Bakyani ${ }^{1} \cdot$ Ameneh Taghizadeh $^{1} \cdot$ Amir Nematollahi Sarvestani $^{1} \cdot$ Feridun Esmaeilzadeh $^{1}$. \\ Dariush Mowla ${ }^{1}$
}

Received: 25 May 2017 / Accepted: 26 November 2017 / Published online: 3 January 2018

(c) The Author(s) 2018. This article is an open access publication

\begin{abstract}
A significant percentage of hydrocarbon reservoirs around the world is fractured. Moreover, the major part of gas reservoirs in Iran is also fractured type, so the existence of an in-house software is necessary. In this study, an efficient, user-friendly, and indigenous simulation of a three-dimensional black oil fractured dry gas reservoir has been developed through IMPES method with the two-phase flow of gas and water. The presented simulator, which was written by $\mathrm{C}^{++}$language and was known as fracture dry gas reservoir simulator, uses the implicit pressure and explicit saturation method for solving the equations. Also, effect of gravity pressure is neglected and effect of the capillary is considered in equations. By this simulator, we can investigate the dry gas reservoirs behavior with fractures. Darcy or non-Darcy fracture and matrix flow, Cartesian, cylindrical, and combination of Cartesian-cylindrical reservoir gridding, single porosity, dual porosity-single permeability, and dual porosity-dual permeability modeling are abilities of this simulator too. Additionally, this simulator is able to make outputs (such as pressure) at any given specific radius and time interval as numerical and/or graphical output in so little run time. Also, this simulator has PVT box and gridding box for doing the calculation of PVT and gridding. PVT box contains new correlations and EOS in comparison with another reservoir simulator. Gridding box makes us be able to simulate fractured dry gas reservoirs and hydraulically fractured well reservoirs too. Finally, the validity of this simulator was verified by comparing the simulation results with the other reservoir simulator (Eclipse) and showed a good compatibility between the developed software and Eclipse results in each time with different conditions such as various gridding conditions, various fluid data conditions and also various well configuration conditions.
\end{abstract}

Keywords Fracture $\cdot$ In-house software $\cdot$ IMPES formulation $\cdot \mathrm{C}^{++}$language $\cdot$ Numerical simulation

List of symbols

$B$

$C$

$C_{\mathrm{f}}$

$C_{\mathrm{t}}$

$J$

K

$k_{\mathrm{r}}$

$h$

$h_{\mathrm{p}}$

$P$

$T$

Ahmadreza Ejraei Bakyani

ahmadrezaejraei@gmail.com

1 Department of Petroleum Engineering, School of Chemical, Petroleum, and Gas Engineering, Shiraz University, Shiraz, Iran

Total compressibility (1/psi)
Formation volume factor ( $\mathrm{rcf} / \mathrm{scf})$

Compressibility (1/psi) $\quad q$

Rock compressibility (1/psi)

Production index (Mscf.cp/D/psi $\left.{ }^{2}\right)$

Absolute permeability (md)

Relative permeability (-)

Productive zone height ( $\mathrm{ft}$ )

Perforated zone height (ft)

Pressure (psi)

Temperature $\left({ }^{\circ} \mathrm{R}\right)$ $t \quad$ Time (s)

$q \quad$ Production flow rate (Mscf/D)

$q_{\mathrm{i}} \quad$ Injection flow rate (Mscf/D)

$r_{\mathrm{w}} \quad$ Well radius $(\mathrm{ft})$

$r_{\mathrm{e}} \quad$ Outer boundary radius (ft)

$\Delta x, \Delta y$, and $\Delta z$ Grid dimension (ft)

$\Delta t \quad$ Time step (s)

$S \quad$ Saturation (-)

$P_{\mathrm{c}} \quad$ Capillary pressure (psi)

$V_{\mathrm{p}} \quad$ Pore volume $\left(\mathrm{ft}^{3}\right)$

$S_{\mathrm{f}} \quad$ Hydraulically fractured skin (-)

$S_{\mathrm{d}} \quad$ Non-Darcy skin (-)

$x_{\mathrm{f}} \quad$ Fracture length (ft)

$h_{\mathrm{f}} \quad$ Fracture height (ft)

$w_{\mathrm{f}} \quad$ Fracture width (in)

$F_{\mathrm{CD}} \quad$ Fracture conductivity (-)

$F_{\text {ND }} \quad$ Non-Darcy function $\left(\mathrm{psi}^{2} / \mathrm{cp} / \mathrm{Mscf}^{2}\right)$

$E \quad$ Elasticity modulus (psi) 


\section{Greek symbols}

$\begin{array}{ll}\rho & \text { Density } \\ \lambda & \text { Mobility } \\ T & \text { Transmissibility } \\ \varphi & \text { Porosity } \\ \mu & \text { Viscosity } \\ \sigma & \text { Shape factor } \\ \nu & \text { Posion ratio } \\ \beta & \text { Coefficient of inertial resistance } \\ \gamma & \text { Specific weight }\end{array}$

\section{Subscripts}

g Gas

w Water

nw Non-wetting phase

w Wetting phase

i Initial

wf Well fluid

f Fracture

m Matrix

\section{Introduction}

The consumption of natural gas has risen so fast (Al-Fattah and Startzman 1999).

However, when oil production has passed its peak, concludes that natural gas sources will be the essential source of energy for supporting world's power in the next decades. In these conditions, a numerical simulation can be helpful in gas reservoir source estimation. A program is a tool which, when properly applied, can provide an estimation (Staggs and Herbeck 1971; Aziz and Settari 1999). The existence of a specific simulator to apply in the fractured dry gas reservoir can be helpful in properties calculation, resource and history estimation, better recognition of these reservoirs as a major energy source and so on. This simulator is developed in order to the accurate investigation of dry gas reservoir fluid flow with fractures by focusing on dry gas fluids parameters and fractures parameters too. In past years, some works had been carried out on dry gas reservoir modeling and simulation, but no specific simulator had been developed that can be covered all problems of these reservoirs and expressed all parameters of dry gas fluid flow and fractures and led to a high accuracy.

Previous works which had been carried out on fractured gas reservoirs are listed below.

The radius of accumulated condensates region around the well in a gas condensate reservoir as a function of time, gas velocity, rock and fluid properties was determined (Muskat 1949). Flow equations in fracture were developed for the first time (Barrenblatt et al. 1960). Primary theory for single-phase flow in fracture was developed (Warren and Root 1963). Then, these equations for fluid flow numerical simulation by Kazemi et al. were applied. The first model for gas condensate pressure and saturation prediction around production well was developed (Kniazeff and Naville 1965; Eilerts et al. 1965). Gas condensate recovery by computer programming and finite difference method was modeled (Eilerts et al. 1965). Pseudo-pressure for gas phase was developed for the first time to investigate of gas condensate accumulation in steadystate regime (O'Dell and Miller 1967). A simulator for reservoir simulation with compositional method was developed (Roebuck and Henderson 1969). Kazemi considered block matrix as a cylindrical thick layer and fracture as a thin layer between them. Then, by consideration no connection between block matrix and boundary conditions, solved flow equations and determined pressure as a function of time and location (Kazemi 1969). Gas condensate phase behavior on porous media was investigated (Saeidi and Handy 1974). A model was developed which fracture network in Warren-Root model was replaced with a vertical fracture (Cinco-Ley et al. 1985). Triple porosity model with two various porosity block matrix was developed (Abdassah and Ershaghi 1986). An equation for determination fracture network permeability was developed (Jones et al. 1988). Effect of surface tension on gas and condensate relative permeability was investigated (Asar and Handy 1988). A gas condensate reservoir including a mixture of three hydrocarbons with compositional and fully implicit method was modeled (Jones and Raghavan 1988). Gas injection into gas condensate reservoir in 2-D was simulated, and simulation results with finite difference method were compared (Chang et al. 1991). Effect of gas condensate accumulation on production reduction was investigated (Afidick et al. 1994). By gridding around well, a reservoir was simulated (Malachowski et al. 1995). A method for determination of gas relative permeability in oil reservoir with associate gas was developed (Hatzignatiou and Reynolds 1996). A model was developed which block matrix size is not same in it, but in the Warren-Root model is same (Rice 1997). Dual porosity-dual permeability model for single-phase flow was developed (Cather et al. 1998). Phase behavior around well according to non-Darcy flow was modeled (Coats et al. 1998). A method for modeling gas and condensate relative permeability was determined (Fevang and Whitson 1999). Relative permeability in gas condensate reservoir as a function of the capillary number was determined (Henderson et al. 2000). An experimental method was developed which relative permeability around well in steady-state, high-pressure and highvelocity conditions was determined (Mott 2000). Effect of the capillary number and the non-Darcy flow on phase's relative permeability in gas condensate reservoir were investigated (Penuela et al. 2002). Equations of gas injection into gas condensate reservoir were solved, and MMP was determined (Seto et al. 2003). A method for determining gas condensate ratio was developed (Mott 2003). Miscibility variation in 
gas injection into gas condensate reservoir with numerical method was investigated (Hoier et al. 2004). Four porosity model including fracture network with three various properties fractures was developed (Dreier et al. 2004). MMP in gas condensate reservoir by injecting NGL and $\mathrm{CO}_{2}$ with the help of Peng-Robinson, Patel-Teja, Patel-Teja-Valderrama and Esmaielzadeh-Roshanfekr EOS was determined (Esmaeilzadeh and Roshanfekr 2006). Simulation of gas condensate well with pseudo-pressure method was developed (Bonyadi 2006). A 2-D and single-phase model of fracture gas reservoir was developed (Shane and Hattingh 2009). Another technique for applying mathematical modeling in petroleum reservoirs is the model based on the adaptive neuro-fuzzy inference system (ANFIS) that was applied to determine the oil- $\mathrm{CO}_{2}$ molecular diffusion coefficient in the secondary and tertiary production mechanisms such as $\mathrm{CO}_{2}$ miscible injection as well as applying the particle swarm optimization algorithm to optimize the ANFIS model parameters, that can be applied in the numerical simulation of petroleum reservoirs (Ejraei Bakyani et al. 2016a). Finally, based on the linear regression technique, several empirical relationships of two-phase (gas-water) relative permeabilities through fracture were obtained for the various conditions both the smooth and the rough parallel fractures during the imbibition and the drainage mechanisms that can be applied in the numerical simulation of two-phase flow through fractured reservoirs (Ejraei Bakyani et al. 2016b).

In next parts, equations are derived for dual porosity-dual permeability fractured reservoirs with the gas and water twophase flow and the effect of capillary pressure is considered and the results are discussed.

\section{Numerical simulation}

\section{Governing equations}

Conservation laws in reservoir simulation consist of mass, energy and momentum conservation. By writing mass balance in each grid block, mass input and output difference, this purpose is achieved. After this discretization starts by applying a finite difference equation for the gas and water flow in the grid system. This finite difference equation shows the mass difference in each grid, so these equations called the mass conservation (Wattenbarger 2002; Putra and Schechter 2003):

$\dot{m}_{\mathrm{im}}-\dot{m}_{\mathrm{om}}-\dot{m}_{\mathrm{mf}}=\dot{m}_{\mathrm{am}}$

$\dot{m}_{\mathrm{if}}-\dot{m}_{\mathrm{of}} \pm \dot{m}_{\mathrm{s}}+\dot{m}_{\mathrm{mf}}=\dot{m}_{\mathrm{af}}$

where $\dot{m}_{\text {im }}$ and $\dot{m}_{\text {if }}$ are input matrix and fractures mass flow rate, respectively. $\dot{m}_{\text {om }}$ and $\dot{m}_{\text {of }}$ are output matrix and fractures mass flow rate, respectively. $\dot{m}_{\mathrm{mf}}$, which is the mass flow rate per volume unit of matrix, shows flow transfer between matrix and fracture. $\dot{m}_{\mathrm{s}}$ is the production or injection mass flow rate in a fracture.

However, for input, output, and accumulation term and replacing in Eqs. (1) and (2), we have:

$\left.\dot{m}_{\mathrm{im}}\right) x=\left(\overline{\rho_{\alpha}} u_{\alpha}\right)_{\mathrm{m}}$

$\left.\dot{m}_{\mathrm{if}}\right) x=\left(\overline{\rho_{\alpha}} u_{\alpha}\right)_{\mathrm{f}}$

$\left.\dot{m}_{\mathrm{om}}\right) x+\Delta x=\left(\overline{\rho_{\alpha}} u_{\alpha}\right)_{\mathrm{m}}$

$\left.\dot{m}_{\mathrm{of}}\right) x+\Delta x=\left(\overline{\rho_{\alpha}} u_{\alpha}\right)_{\mathrm{f}}$

Accume $=\frac{\partial}{\partial t}\left(m_{l}\right) \Delta t$

$\dot{m}_{\alpha}=\bar{\rho}_{\alpha} u_{\alpha}$

$m_{\alpha}=\overline{\rho_{\alpha}} \emptyset s_{\alpha}$

$\overline{\rho_{\alpha}}=\frac{\rho_{\mathrm{STC}}}{B_{\alpha}}$

$q_{\alpha}=\frac{\overline{q_{\alpha}}}{B_{\alpha}}$

$-\nabla m_{\alpha \mathrm{f}}+\dot{m}_{\mathrm{mf}}=\frac{\partial}{\partial t} m_{\alpha \mathrm{f}}+\overline{q_{\alpha}}$

$-\nabla m_{\alpha \mathrm{m}}-\dot{m}_{\mathrm{mf}}=\frac{\partial}{\partial t} m_{\alpha \mathrm{m}}$

$-\nabla\left(\overline{\rho_{\alpha}} u_{\alpha}\right)_{\mathrm{f}}+\overline{\rho_{\alpha}} u_{\mathrm{mf}}=\frac{\partial}{\partial t}\left(\overline{\rho_{\alpha}} \emptyset s_{\alpha}\right)_{\mathrm{f}}+\overline{q_{\alpha}}$

$-\nabla\left(\overline{\rho_{\alpha}} u_{\alpha}\right)_{\mathrm{m}}-\overline{\rho_{\alpha}} u_{\mathrm{mf}}=\frac{\partial}{\partial t}\left(\overline{\rho_{\alpha}} \emptyset s_{\alpha}\right)_{\mathrm{m}}$

$-\nabla\left(\frac{\rho_{\mathrm{STC}}}{B_{\alpha}} u_{\alpha}\right)_{\mathrm{f}}+\frac{\rho_{\mathrm{STC}}}{B_{\alpha}} u_{\mathrm{mf}}=\frac{\partial}{\partial t}\left(\frac{\rho_{\mathrm{STC}}}{B_{\alpha}} \emptyset_{\alpha}\right)_{\mathrm{f}}+\rho_{\mathrm{STC}} q_{\alpha}$

$-\nabla\left(\frac{\rho_{\mathrm{STC}}}{B_{\alpha}} u_{\alpha}\right)_{\mathrm{m}}-\frac{\rho_{\mathrm{STC}}}{B_{\alpha}} u_{\mathrm{mf}}=\frac{\partial}{\partial t}\left(\frac{\rho_{\mathrm{STC}}}{B_{\alpha}} \emptyset_{s_{\alpha}}\right)_{\mathrm{m}}$

Pore volume of each grid is:

$V_{\mathrm{p}}=\Delta x \Delta y \Delta z \emptyset$

Gas accumulation rate in fracture and matrix grid or RHS of continuity equation is: 
$=\frac{\rho_{g \mathrm{STC}}}{\Delta t}\left[\left(\frac{V_{\mathrm{p}} S_{\mathrm{g}}}{B_{\mathrm{g}}}\right)_{\mathrm{f}}^{n+1}-\left(\frac{V_{\mathrm{p}} S_{\mathrm{g}}}{B_{\mathrm{g}}}\right)_{\mathrm{f}}^{n}\right]$

$=\frac{\rho_{\mathrm{gSTC}}}{\Delta t}\left[\left(\frac{V_{\mathrm{p}} S_{\mathrm{g}}}{B_{\mathrm{g}}}\right)_{\mathrm{m}}^{n+1}-\left(\frac{V_{\mathrm{p}} S_{\mathrm{g}}}{B_{\mathrm{g}}}\right)_{\mathrm{m}}^{n}\right]$

where $q_{\alpha}, u_{\alpha}, \rho_{\alpha}, S_{\alpha}, B_{\alpha}, \Delta x, \Delta y, \Delta z, \Delta t, n$, and $n+1$ are rate, velocity, density, saturation, formation volume factor of phase $\alpha$, grid dimensions, time step, nth time step, and $n+1$ th time step, respectively.

LHS of continuity equation is:

$$
\begin{aligned}
\text { Netmassin } & =\rho_{\alpha \mathrm{STC}} q_{(i-1) f \rightarrow i}+\rho_{\alpha \mathrm{STC}} q_{(i+1) f \rightarrow i}+\rho_{\alpha \mathrm{STC}} q_{\mathrm{well}}+\rho_{\alpha \mathrm{STC}} q_{\mathrm{mf}} \\
& =\rho_{\alpha \mathrm{STC}} q_{(i-1) m \rightarrow i}+\rho_{\alpha \mathrm{STC}} q_{(i+1) m \rightarrow i}-\rho_{\alpha \mathrm{STC}} q_{\mathrm{mf}}
\end{aligned}
$$

When we have flowing into grid $q_{\text {well }}$ is positive and flowing out of grid $q_{\text {well }}$ is negative.

Finally with mass balance on fracture and matrix, we have:

$$
\begin{aligned}
& \frac{\rho_{\mathrm{STC}}}{B_{\alpha}} q_{(i-1) f \rightarrow i}+\frac{\rho_{\mathrm{STC}}}{B_{\alpha}} q_{(i+1) f \rightarrow i}+\frac{\rho_{\mathrm{STC}}}{B_{\alpha}} q_{\mathrm{mf}} \\
& =\rho_{\mathrm{STC}} q_{\alpha}+\frac{\frac{\rho_{\mathrm{STC}}}{B_{\alpha}}}{\Delta t}\left[\left(V_{\mathrm{p}} S_{\alpha}\right)_{\mathrm{f}}^{n+1}-\left(V_{\mathrm{p}} S_{\alpha}\right)_{\mathrm{f}}^{n}\right] \\
& \frac{\rho_{\mathrm{STC}}}{B_{\alpha}} q_{(i-1) m \rightarrow i}+\frac{\rho_{\mathrm{STC}}}{B_{\alpha}} q_{(i+1) m \rightarrow i}-\frac{\rho_{\mathrm{STC}}}{B_{\alpha}} q_{\mathrm{mf}} \\
& =\frac{\frac{\rho_{\mathrm{STC}}}{B_{\alpha}}}{\Delta t}\left[\left(V_{\mathrm{p}} S_{\alpha}\right)_{\mathrm{m}}^{n+1}-\left(V_{\mathrm{p}} S_{\alpha}\right)_{\mathrm{m}}^{n}\right]
\end{aligned}
$$

By simplification of the above equations, we have:

For fractures:

$$
\begin{aligned}
& \frac{1}{B_{\alpha}} q_{(i-1) f \rightarrow i}+\frac{1}{B_{\alpha}} q_{(i+1) f \rightarrow i}+\frac{1}{B_{\alpha}} q_{\mathrm{mf}} \\
& =q_{\alpha}+\frac{1}{\Delta t}\left[\left(\frac{V_{\mathrm{p}} S_{\alpha}}{B_{\alpha}}\right)_{\mathrm{f}}^{n+1}-\left(\frac{V_{\mathrm{p}} S_{\alpha}}{B_{\alpha}}\right)_{\mathrm{f}}^{n}\right]
\end{aligned}
$$

For matrix:

$$
\begin{aligned}
& \frac{1}{B_{\alpha}} q_{(i-1) m \rightarrow i}+\frac{1}{B_{\alpha}} q_{(i+1) m \rightarrow i}-\frac{1}{B_{\alpha}} q_{\mathrm{mf}} \\
& =q_{\alpha}+\frac{1}{\Delta t}\left[\left(\frac{V_{\mathrm{p}} S_{\alpha}}{B_{\alpha}}\right)_{\mathrm{m}}^{n+1}-\left(\frac{V_{\mathrm{p}} S_{\alpha}}{B_{\alpha}}\right)_{\mathrm{m}}^{n}\right]
\end{aligned}
$$

where the flow into the grid block is called the positive flow, the flow out of the grid block is called the negative flow. For flow rate, we need Darcy's law for flow between the centers of the grid blocks. The flow distance, $\Delta x$, is the distance between the centers of the grid blocks. The grid block pressures are considered the center of the grid blocks pressures.

Flow from the right of grid block $i+1$ to grid block $i$ is
Darcy's law for fractured:

$$
\begin{gathered}
\frac{1}{B_{\alpha}} q_{\alpha(i-1) f \rightarrow i}\left(\frac{\mathrm{SCF}(\text { Standard Cubic Feet })}{D(\text { Day })}\right) \\
=\frac{0.00633 k_{\mathrm{f}} k_{\mathrm{r} \alpha \mathrm{f}}}{\mu_{\alpha} B_{\alpha}}\left(\frac{P_{i+1}-P_{i}}{\Delta x}\right) \Delta y \Delta z \\
=\frac{0.00633 k_{\mathrm{f}} \Delta y \Delta z}{\Delta x}\left(\frac{k_{\mathrm{r}}}{B \mu}\right)_{\alpha \mathrm{f}}\left(P_{i+1}-P_{i}\right)
\end{gathered}
$$

The subscript $\alpha$ represents water or gas phase.

Darcy's law for the matrix:

$$
\begin{aligned}
\frac{1}{B_{\alpha}} q_{\alpha(i+1) m \rightarrow i}\left(\frac{\mathrm{SCF}}{D}\right) & =\frac{0.00633 k_{\mathrm{m}} k_{\mathrm{r} \alpha \mathrm{m}}}{\mu_{\alpha} B_{\alpha}}\left(\frac{P_{i+1}-P_{i}}{\Delta x}\right) \Delta y \Delta z \\
& =\frac{0.00633 k_{\mathrm{m}} \Delta y \Delta z}{\Delta x}\left(\frac{k_{\mathrm{r}}}{B \mu}\right)_{\alpha \mathrm{m}}\left(P_{i+1}-P_{i}\right)
\end{aligned}
$$

where $q_{\mathrm{mf}}$ is the rate of fluid transfer between matrix and fracture in a grid block and is given by

$q_{\mathrm{mf}}=\frac{0.00633 k_{\mathrm{m}} k_{r \alpha \mathrm{m}}}{\mu_{\alpha}} \sigma \Delta x \Delta y \Delta z\left(P_{\alpha \mathrm{m}}-P_{\alpha \mathrm{f}}\right)$

In above equation, $\sigma$ is the shape factor and define as below:

$\sigma=\frac{C}{L^{2}}$

Warren and Root define the shape factor as below:

$\sigma=\frac{60}{L_{x}^{2}+L_{y}^{2}+L_{z}^{2}}$

The first term is called "transmissibility," now it is defined:

$\left(T_{i+\frac{1}{2}}\right)_{\mathrm{f}}=0.00633 \frac{k_{\mathrm{f}} \Delta y \Delta z}{\Delta x}$

$\left(T_{i+\frac{1}{2}}\right)_{\mathrm{m}}=0.00633 \frac{k_{\mathrm{m}} \Delta y \Delta z}{\Delta x}$

The subscript $i+1 / 2$ indicates that the coefficient is applied between grid blocks $i$ and $i+1, i+1 / 2$. The next term in Eqs. (31) and (32) is called mobility " $\lambda$." Its value changes with time and is defined as:

$$
\begin{aligned}
& \lambda_{g f i+\frac{1}{2}=\left(\frac{k_{\mathrm{r}}}{\mu B}\right)_{\alpha f i+1 / 2}} \\
& \lambda_{g m i+\frac{1}{2}=\left(\frac{k_{\mathrm{r}}}{\mu B}\right)_{\alpha \mathrm{m} i+1 / 2}}
\end{aligned}
$$

Absolute permeability, relative permeability and viscosity of both phases, and porosity in the represented equation need to be averaged according to Table 1 (Aziz and Settari 1999): 
Table 1 Method of averaging

\begin{tabular}{ll}
\hline Parameter & Method of averaging \\
\hline Absolute permeability & Harmonic averaging \\
Porosity & Arithmetic averaging \\
Relative permeability & Upstream weighting \\
Viscosity & Arithmetic averaging \\
Formation volume factor & Arithmetic averaging \\
\hline
\end{tabular}

The general material balance equation for two-phases in 3-D are as follow:

For fractures:

$$
\begin{aligned}
& \left(\frac{k_{\mathrm{r}}}{\mu B}\right)_{\alpha \mathrm{fi} i-\frac{1}{2}} T_{\mathrm{f} i-\frac{1}{2}}\left(P_{\alpha \mathrm{f} i-1, j, k}-P_{\alpha \mathrm{f} i, j, k}\right)+\left(\frac{k_{\mathrm{r}}}{\mu B}\right)_{\alpha \mathrm{fi} i+\frac{1}{2}} \\
& \times T_{\mathrm{f} i+\frac{1}{2}}\left(P_{\alpha f i+1, j, k}-P_{\alpha f i, j, k}\right) \\
& +\left(\frac{k_{\mathrm{r}}}{\mu B}\right)_{\alpha \mathrm{fj}-\frac{1}{2}} T_{\mathrm{fj}-\frac{1}{2}}\left(P_{\alpha \mathrm{fi}, j-1, k}-P_{\alpha \mathrm{fi}, j, k}\right) \\
& +\left(\frac{k_{\mathrm{r}}}{\mu B}\right)_{\alpha \mathrm{fj}+\frac{1}{2}} T_{\mathrm{fj}+\frac{1}{2}}\left(P_{\alpha \mathrm{fi} i j+1, k}-P_{\alpha \mathrm{fi} i, j, k}\right) \\
& +\left(\frac{k_{\mathrm{r}}}{\mu B}\right)_{\alpha \mathrm{ffk}-\frac{1}{2}} T_{\mathrm{f} k-\frac{1}{2}}\left(P_{\alpha \mathrm{fi} i, j, k-1}-P_{\alpha \mathrm{fi} i, j, k}\right) \\
& +\left(\frac{k_{\mathrm{r}}}{\mu B}\right)_{\alpha f k+\frac{1}{2}} T_{f k+\frac{1}{2}}\left(P_{\alpha f i, j, k+1}-P_{\alpha f i, j, k}\right) \\
& +\lambda_{\alpha \mathrm{mf}}\left(P_{\alpha \mathrm{m} i, j, k}-P_{\alpha \mathrm{ff} i, j, k}\right) \\
& =q_{\alpha}+\frac{1}{\Delta t}\left[\left(\frac{V_{\mathrm{p}} S_{\alpha}}{B_{\alpha}}\right)_{\mathrm{f}}^{n+1}-\left(\frac{V_{\mathrm{p}} S_{\alpha}}{B_{\alpha}}\right)_{\mathrm{f}}^{n}\right]
\end{aligned}
$$

For matrix:

$$
\begin{aligned}
\left(\frac{k_{\mathrm{r}}}{\mu B}\right)_{\alpha \mathrm{m} i-\frac{1}{2}} T_{\mathrm{m} i-\frac{1}{2}}\left(P_{\alpha \mathrm{m} i-1, j, k}-P_{\alpha \mathrm{m} i, j, k}\right)+\left(\frac{k_{r}}{\mu B}\right)_{\alpha \mathrm{m} i+\frac{1}{2}} \\
\quad \times T_{\mathrm{m} i+\frac{1}{2}}\left(P_{\alpha \mathrm{m} i+1, j, k}-P_{\alpha \mathrm{m} i, j, k}\right) \\
\quad+\left(\frac{k_{\mathrm{r}}}{\mu B}\right)_{\alpha \mathrm{m} j-\frac{1}{2}} T_{m j-\frac{1}{2}}\left(P_{\alpha m i, j-1, k}-P_{\alpha m i, j, k}\right) \\
\quad+\left(\frac{k_{\mathrm{r}}}{\mu B}\right)_{\alpha \mathrm{m} j+\frac{1}{2}} T_{m j+\frac{1}{2}}\left(P_{\alpha m i, j+1, k}-P_{\alpha \mathrm{m} i, j, k}\right)+\left(\frac{k_{r}}{\mu B}\right)_{\alpha \mathrm{m} k-\frac{1}{2}} \\
\quad \times T_{\mathrm{m} k-\frac{1}{2}}\left(P_{\alpha \mathrm{m} i, j, k-1}-P_{\alpha \mathrm{m} i, j, k}\right) \\
\quad+\left(\frac{k_{\mathrm{r}}}{\mu B}\right)_{\alpha \mathrm{m} k+\frac{1}{2}} T_{m k+\frac{1}{2}}\left(P_{\alpha m i, j, k+1}-P_{\alpha \mathrm{m} i, j, k}\right) \\
\quad-\lambda_{\alpha \mathrm{m} f}\left(P_{\alpha \mathrm{m} i, j, k}-P_{\alpha f i, j, k}\right) \\
=\frac{1}{\Delta t}\left[\left(\frac{V_{\mathrm{p}} S_{\alpha}}{B_{\alpha}}\right)_{m}^{n+1}-\left(\frac{V_{\mathrm{p}} S_{\alpha}}{B_{\alpha}}\right)_{m}^{n}\right]
\end{aligned}
$$

\section{IMPES method}

IMPES refers to "Implicit Pressure Explicit Saturation." But the fully implicit method calculates the main variables at the same time (all primary variables at the new time level are determined simultaneously), the IMPES method solves pressure equations at the new time level by using saturation equations at the old time level, then the pressure equations at the new time level are solved to calculate the saturations at the new time level explicitly. The type of method that equations are solved effects on the level of ease, accuracy, and cost of the simulation.

Different studies have been applied on implicit pressure, explicit saturation "the IMPES" method (Calvin and Dalton 1990; Hallam and Kin 2003; Ansah 1996).

The gas symmetrical flow coefficients are defined as follow: (for the east direction for instance):

$a_{\alpha f i+\frac{1}{2}}=\left(\frac{k_{\mathrm{r}}}{\mu B}\right)_{\alpha \mathrm{fi} i+\frac{1}{2}} T_{\mathrm{fi} i+\frac{1}{2}}$

$a_{\alpha \mathrm{m} i+\frac{1}{2}}=\left(\frac{k_{\mathrm{r}}}{\mu B}\right)_{\alpha \mathrm{m} i+\frac{1}{2}} T_{\mathrm{m} i+\frac{1}{2}}$

The 3-D finite difference equation of gas material balance equation is:

For fractures:

$$
\begin{aligned}
\Delta a_{\alpha \mathrm{f}} \Delta P_{\alpha \mathrm{f}}= & a_{\alpha f i-\frac{1}{2}}\left(P_{\alpha f i-1, j, k}-P_{\alpha f i j, j, k}\right)+a_{\alpha f i+\frac{1}{2}}\left(P_{\alpha f i+1, j, k}-P_{\alpha f i j, j, k}\right) \\
& +a_{\alpha f j-\frac{1}{2}}\left(P_{\alpha f i, j-1, k}-P_{\alpha f i, j, k}\right)+a_{\alpha f j+\frac{1}{2}}\left(P_{\alpha f i, j+1, k}-P_{\alpha f i j, j, k}\right) \\
& +a_{\alpha f k-\frac{1}{2}}\left(P_{\alpha f i j, j, k-1}-P_{\alpha f i j, j, k}\right)+a_{\alpha f k+\frac{1}{2}}\left(P_{\alpha f i j, j, k+1}-P_{\alpha f i j, j, k}\right)
\end{aligned}
$$

For matrix:

$$
\begin{aligned}
\Delta a_{\alpha \mathrm{m}} \Delta P_{\alpha \mathrm{m}}= & a_{\alpha \mathrm{m} i-\frac{1}{2}}\left(P_{\alpha \mathrm{m} i-1, j, k}-P_{\alpha \mathrm{m} i, j, k}\right) \\
& +a_{\alpha \mathrm{m} i+\frac{1}{2}}\left(P_{\alpha \mathrm{m} i+1, j, k}-P_{\alpha \mathrm{m} i, j, k}\right) \\
& +a_{\alpha \mathrm{m} j-\frac{1}{2}}\left(P_{\alpha \mathrm{m} i, j-1, k}-P_{\alpha \mathrm{m} i, j, k}\right) \\
& +a_{\alpha \mathrm{m} j+\frac{1}{2}}\left(P_{\alpha \mathrm{m} i, j+1, k}-P_{\alpha \mathrm{m} i, j, k}\right) \\
& +a_{\alpha \mathrm{m} k-\frac{1}{2}}\left(P_{\alpha \mathrm{m} i, j, k-1}-P_{\alpha \mathrm{m} i, j, k}\right) \\
& +a_{\alpha \mathrm{m} k+\frac{1}{2}}\left(P_{\alpha \mathrm{m} i, j, k+1}-P_{\alpha \mathrm{m} i, j, k}\right)
\end{aligned}
$$

The general material balance equation can be derived as: For fractures:

$$
\Delta a_{\alpha \mathrm{f}} \Delta P_{\alpha \mathrm{f}}+\lambda_{\alpha \mathrm{mf}}\left(P_{\alpha \mathrm{m}}-P_{\alpha \mathrm{f}}\right)=q_{\alpha}+\frac{1}{\Delta t}\left[\left(\frac{V_{\mathrm{p}} S_{\alpha}}{B_{\alpha}}\right)_{\mathrm{f}}^{n+1}-\left(\frac{V_{\mathrm{p}} S_{\alpha}}{B_{\alpha}}\right)_{\mathrm{f}}^{n}\right]
$$

For water phase, the same equations can be written. 
For matrix:

$\Delta a_{\alpha \mathrm{m}} \Delta P_{\alpha \mathrm{m}}-\lambda_{\alpha \mathrm{mf}}\left(P_{\alpha \mathrm{m}}-P_{\alpha \mathrm{f}}\right)=\frac{1}{\Delta t}\left[\left(\frac{V_{\mathrm{p}} S_{\alpha}}{B_{\alpha}}\right)_{\mathrm{m}}^{n+1}-\left(\frac{V_{\mathrm{p}} S_{\alpha}}{B_{\alpha}}\right)_{\mathrm{m}}^{n}\right]$

For the 3-D system, rearranging the (41) and (42) equations will give the following saturation equations:

$S_{\alpha \mathrm{f}}^{n+1}=\frac{B_{a \mathrm{f}}^{n+1}}{V_{\mathrm{pf}}^{n+1}}\left[\left(\frac{V_{\mathrm{p}} S_{\alpha}}{B_{\alpha}}\right)_{\mathrm{f}}^{n}+\Delta t\left(\Delta a_{\alpha \mathrm{f}} \Delta P_{\alpha \mathrm{f}}^{n+1}+\lambda_{\alpha \mathrm{mf}}\left(P_{\alpha \mathrm{m}}-P_{\alpha \mathrm{f}}\right)-q_{\alpha}\right)\right]$

$S_{\alpha \mathrm{m}}^{n+1}=\frac{B_{a \mathrm{~m}}^{n+1}}{V_{\mathrm{pm}}^{n+1}}\left[\left(\frac{V_{\mathrm{p}} S_{\alpha}}{B_{\alpha}}\right)_{\mathrm{m}}^{n}+\Delta t\left(\Delta a_{\alpha \mathrm{m}} \Delta P_{\alpha \mathrm{m}}^{n+1}-\lambda_{\alpha \mathrm{mf}}\left(P_{\alpha \mathrm{m}}-P_{\alpha \mathrm{f}}\right)\right)\right]$

Also, we need to auxiliary equations to solve the system of equations as follows:

$S_{\mathrm{gf}}+S_{\mathrm{wf}}=1$

$S_{\mathrm{gm}}+S_{\mathrm{wm}}=1$

All equations are defined for gas pressure. So, by applying capillary pressure "difference of gas and water pressure" at any matrix grid block, we can substitute Eq. (47) instead of water pressure in above equations.

$P_{\mathrm{wm}}=P_{\mathrm{gm}}-P_{\mathrm{cgwm}}$

Capillary pressure in fracture is neglected, so we have:

$P_{\text {cgwf }}=0$

$P_{\mathrm{wf}}=P_{\mathrm{gf}}$

Now, we have equations with an unknown pressure " $p_{n+1}$," as pore volume equations.

By substituting the compressibility equations such as gas and water compressibility and formation compressibility into the pore volume equation and simplifying right side of this equation and substituting total compressibility, total rate is defined as:

$q_{\mathrm{t}}=B_{\mathrm{w}}^{n+1} q_{\mathrm{w}}+B_{\mathrm{g}}^{n+1} q_{\mathrm{g}}$

$C_{\mathrm{t}}=C_{\mathrm{f}}+C_{\mathrm{w}} S_{\mathrm{w}}^{n+1}+C_{\mathrm{g}} S_{\mathrm{g}}^{n+1}$

For fractures:

$$
\begin{aligned}
B_{\mathrm{wf}}^{n+1} & {\left[\Delta a_{\mathrm{wf}} \Delta P_{\mathrm{gf}}^{n+1}+\lambda_{\mathrm{wmf}}\left(P_{\mathrm{gm}}^{n}-P_{\mathrm{cwgm}}^{n}-P_{\mathrm{gf}}^{n}\right)\right] } \\
& +B_{\mathrm{gf}}^{n+1}\left[\Delta a_{\mathrm{gf}} \Delta P_{\mathrm{gf}}^{n+1}+\lambda_{\mathrm{gmf}}\left(P_{\mathrm{gm}}^{n}-P_{\mathrm{gf}}^{n}\right)\right] \\
= & \frac{V_{\mathrm{pf}}^{n} C_{\mathrm{t}}}{\Delta t}\left(P_{\mathrm{gf}}^{n+1}-P_{\mathrm{gf}}^{n}\right) \pm B_{\mathrm{wf}}^{n+1} q_{\mathrm{w}} \pm B_{\mathrm{gf}}^{n+1} q_{\mathrm{g}}
\end{aligned}
$$

$T_{1}=B_{\mathrm{wf}}^{n+1} \lambda_{\mathrm{wmf}}+B_{\mathrm{gf}}^{n+1} \lambda_{\mathrm{gmf}}$

$T_{2}=B_{\mathrm{wf}}^{n+1} \lambda_{\mathrm{wmf}}$

The pore volume equation can be rearranged to reach the final form which is as follow:

$$
\begin{aligned}
& B_{\mathrm{wf}}^{n+1} \Delta a_{\mathrm{wf}} \Delta P_{\mathrm{gf}}^{n+1}+B_{\mathrm{gf}}^{n+1} \Delta a_{\mathrm{gf}} \Delta P_{\mathrm{gf}}^{n+1}+T_{1} P_{\mathrm{gm}}^{n} \\
& \quad-T_{2} P_{\mathrm{cgwm}}^{n}-T_{1} P_{\mathrm{gf}}^{n}=\frac{V_{\mathrm{pf}}^{n} C_{\mathrm{t}}}{\Delta t}\left(P_{\mathrm{gf}}^{n+1}-P_{\mathrm{gf}}^{n}\right)+q_{\mathrm{t}}
\end{aligned}
$$

For matrix:

$$
\begin{aligned}
& B_{\mathrm{wm}}^{n+1}\left[\Delta a_{\mathrm{wm}} \Delta P_{\mathrm{gm}}^{n+1}-\lambda_{\mathrm{wmf}}\left(P_{\mathrm{gm}}^{n}-P_{\mathrm{cwgm}}^{n}-P_{\mathrm{gf}}^{n}\right)\right] \\
& \quad+B_{\mathrm{gm}}^{n+1}\left[\Delta a_{\mathrm{gm}} \Delta P_{\mathrm{gm}}^{n+1}-\lambda_{\mathrm{gmf}}\left(P_{\mathrm{gm}}^{n}-P_{\mathrm{gf}}^{n}\right)\right]=\frac{V_{\mathrm{pf}}^{n} C_{\mathrm{t}}}{\Delta t}\left(P_{\mathrm{gm}}^{n+1}-P_{\mathrm{gm}}^{n}\right)
\end{aligned}
$$

To simplify, Eq. (56) is separated:

$T_{3}=B_{\mathrm{wm}}^{n+1} \lambda_{\mathrm{wmf}}+B_{\mathrm{gm}}^{n+1} \lambda_{\mathrm{wmf}}$

$T_{4}=B_{\mathrm{wm}}^{n+1} \lambda_{\mathrm{wmf}}$

$T_{5}=B_{\mathrm{wm}}^{n+1} \Delta a_{\mathrm{wm}}$

The pore volume equation can be rearranged to reach the final form which is as follow:

$$
\begin{aligned}
& \left(B_{\mathrm{wm}}^{n+1} \Delta a_{\mathrm{wm}}+B_{\mathrm{gm}}^{n+1} \Delta a_{\mathrm{gm}}\right) \Delta P_{\mathrm{gm}}^{n+1}-T_{5} \Delta P_{\mathrm{cgwm}}^{n}-T_{3} P_{\mathrm{gm}}^{n} \\
& \quad+T_{4} P_{\mathrm{cgwm}}^{n}+T_{3} P_{\mathrm{gf}}^{n}=\frac{V_{\mathrm{pm}}^{n} C_{\mathrm{t}}}{\Delta t}\left(P_{\mathrm{gm}}^{n+1}-P_{\mathrm{gm}}^{n}\right)
\end{aligned}
$$

The last equation makes up a system of simultaneous linear equations with respect to the unknown pressures. The number of unknowns and equations defined by the user is the number of grid blocks in a given model.

The first and last equations in this set are the governing equations for boundary conditions.

This set of equations can be represented by a matrix equation.

$A \vec{P}=\vec{B}$

where $A$ is the coefficient matrix and $P$ and $B$ are column vectors.

The structure of the coefficient matrix depends on the dimensions of the problem and the ordering of grid blocks. The purpose of applying different grid block-ordering schemes is to reduce the computational work involved in solving a system of finite difference equations. 


\section{Modeling of production and/or injection well}

By these modeling, we able to calculate rates of liquid and gas phases and utilize in the previous parts.

The flow that injected into or produced from a well within a grid block is simulated using an analytical equation. However, the grid block pressure and the flowing well pressure is different because of difference in grid block dimension and well radius.

By assuming that fluid production from or injection into well is same as fluid flow between two grid blocks and by applying the Darcy's law in radial coordinate with the help of the Peaceman's model (Peaceman 1982) we can model the production or injection well. Also, the flow rate terms in the previous parts can be replaced with two constraints, constant flow rate of each phase or constant bottomhole pressure.

\section{PVT calculation}

In this study, the black oil simulation has been developed and calculations of fluid properties are given in the PVT tables as inputs to the simulator.

Also, a PVT box has been added to the simulator as an additional option in the second phase of simulator development that calculates the fluid properties with the help of EOSs and various correlations and given as input to the simulator. It is worth noting that, the PVT box is also capable of flash calculations in compositional simulation and fluid properties calculations in both compositional and black oil simulations.

\section{Flash calculation}

Phase equilibria calculations are taken place in this part for the simulation of the fractured dry gas reservoir with the help of listed equation of states:

- Peng-Robinson EOS (PR)

- Soave-Redlich-Kwong EOS (SRK)

- Esmaeilzadeh-Roshanfekr EOS (ER)

Note that, ER EOS gives very accurate results for gas reservoir simulation that does not exist in the available simulators such as Eclipse and CMG (Esmaeilzadeh and Roshanfekr 2006).

However, for the flash calculation of two-phase flow through the dry gas reservoir, we apply an algorithm as Fig. 1:

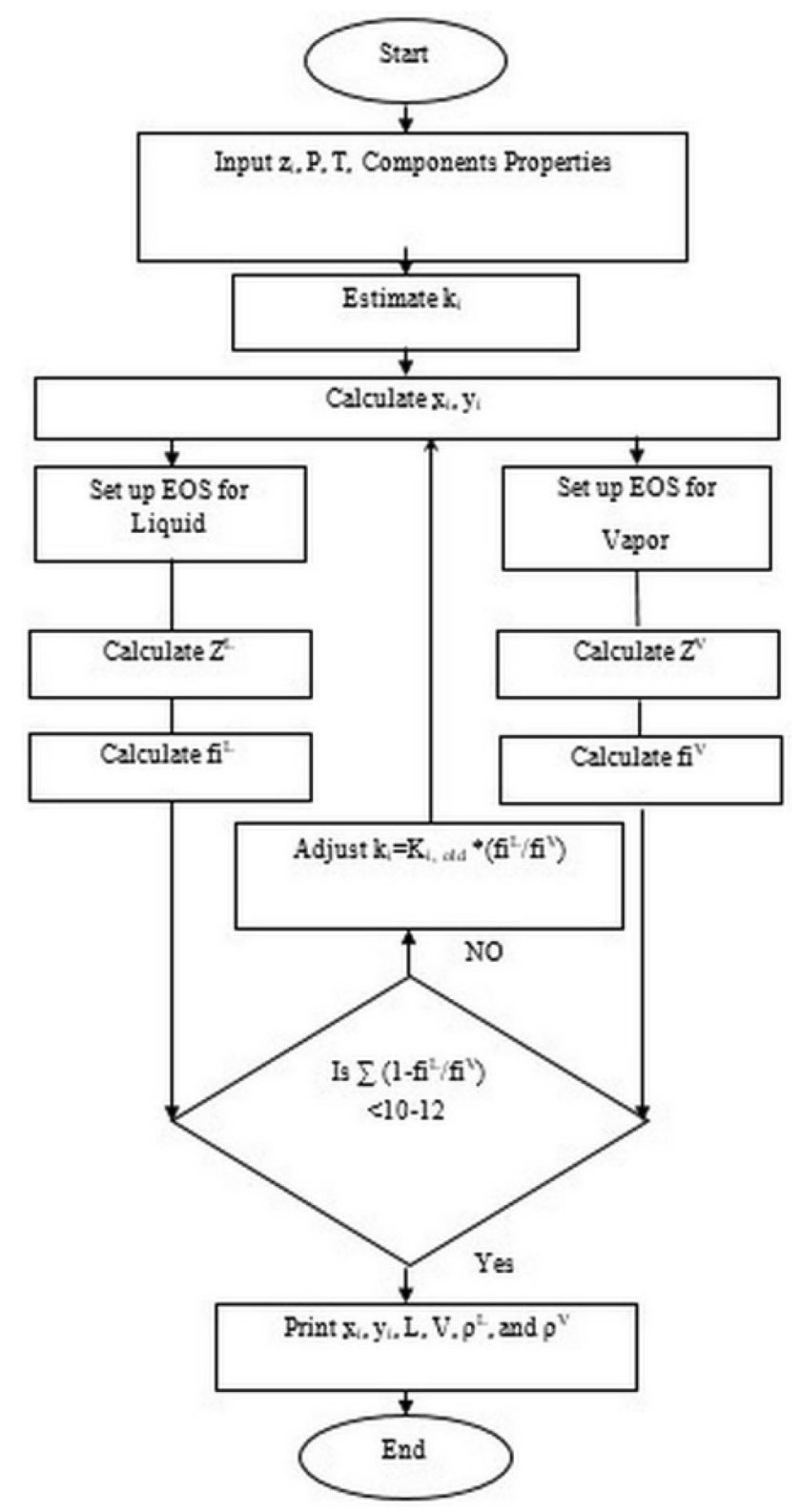

Fig. 1 Iteration method of flash calculation of two-phase flow in equilibrium

\section{Viscosity calculation}

Viscosity calculation is taken place in this part for the simulation of the fractured dry gas reservoir with the help of listed methods:

- Dean-Stiel (1965) for gas viscosity calculation

- Lohrenz-Bray-Clark (1964) for liquid viscosity calculation 


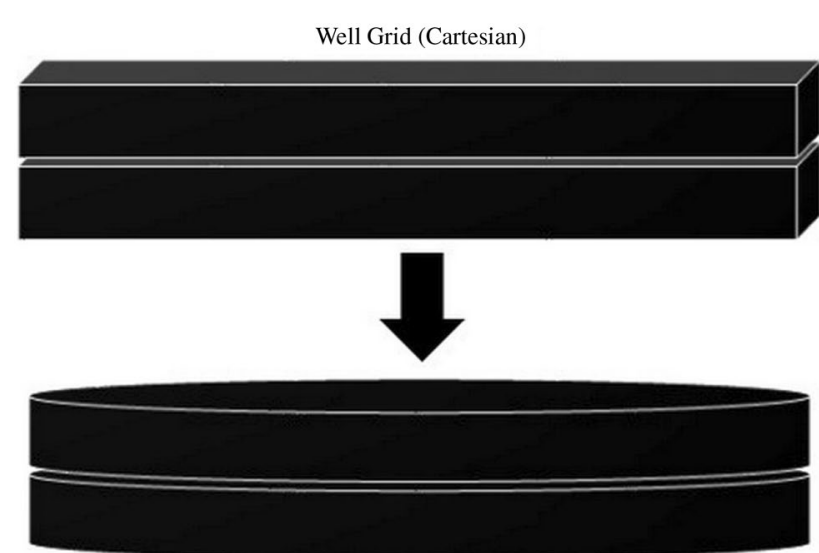

Well Grid (Cylindrical)

Fig. 2 Cylindrical gridding around the well

\section{Gridding}

In this simulator, gridding is taken place in a separated box as a gridding simulator and its output results feed to the main simulator as input. This box is able to gridding in a different way as below:

- Cartesian

- Cylindrical

- Cylindrical-Cartesian

Note that, in this simulator, we can apply cylindrical gridding around the well and Cartesian gridding in other regions as Fig. 2 to achieve accurate results in comparison with whole Cartesian gridding. This is useful to the simulation of hydraulically fractured well reservoirs; in this way that it applies cylindrical gridding to a radius equal to fracture's length and Cartesian gridding out of this radius to achieve the best results in simulation of hydraulically fractured well reservoirs.

\section{Hydraulic fractured well simulation}

Hydraulically created fractures gather fluids from reservoir matrix and provide channels for the fluid to flow into wellbores. Apparently, the productivity of fractured wells depends on two steps: (1) receiving fluids from the formation and (2) transporting the received fluid to the wellbore.

Usually, one of the steps is a limiting step that controls the well-production rate. The efficiency of the first step depends on fracture dimension length " $x_{\mathrm{f}}$ " and height " $h_{\mathrm{f}}$," and the efficiency of the second step depends on fracture permeability " $k_{\mathrm{f}}$ " The importance of each of the steps can be analyzed using the concept of parameter fracture conductivity " $F_{\mathrm{CD}}$ " defined as (Agarwal et al. 1979; Cinco-Ley 1981): ( $w_{\mathrm{f}}$ is fracture width)
$F_{C D}=\frac{k_{f} w_{f}}{k x_{f}}$

In the situations in which the fracture dimension is much less than the drainage area of the well, the long-term productivity of the fractured well can be estimated assuming pseudo-radial flow in the reservoir. Then, the inflow equation can be written as:

$q=\frac{k h\left(\bar{P}-P_{\mathrm{wf}}\right)}{141.2 \mu B\left(\ln \left(\frac{r_{\mathrm{e}}}{r_{\mathrm{w}}}+S_{\mathrm{f}}\right)\right)}$

where $S_{\mathrm{f}}$ is the equivalent skin factor related to the hydraulically fractured well model.

Cinco-Ley et al. (1985) reported a data relationship between fracture conductivity and equivalent skin factor " $S_{\mathrm{f}}$." Valko et al. (1997) converted their data into the following correlation:

$$
\begin{aligned}
S_{\mathrm{f}}= & \frac{1.65-0.328 \ln \left(F_{\mathrm{CD}}\right)+0.116\left(\ln \left(F_{\mathrm{CD}}\right)\right)^{2}}{1+0.180 \ln \left(F_{\mathrm{CD}}\right)+0.064\left(\ln \left(F_{\mathrm{CD}}\right)\right)^{2}+0.05\left(\ln \left(F_{\mathrm{CD}}\right)\right)^{3}} \\
& -\ln \left(\frac{x_{\mathrm{f}}}{r_{\mathrm{w}}}\right)
\end{aligned}
$$

The shape of the fracture varies as predicted by different fracture geometry models:

a. Radial Fracture Model: horizontal fracture, Geertsma and De Klerk (1969).

$$
\bar{w}=0.85\left[\frac{\left.\mu q_{i}(1-v) R\right)}{E}\right]^{\frac{1}{4}}
$$

b. The KGD Model: vertical fracture, fracture width varies horizontally and remains constant vertically along the pay zone, Khristianovich and Zheltov (1955); Geertsma and De Klerk (1969).

$$
\bar{w}=0.34\left[\frac{\left.\mu q_{i}\left(1-v^{2}\right) x_{\mathrm{f}}^{2}\right)}{E h_{\mathrm{f}}}\right]^{\frac{1}{4}}\left(\frac{\pi}{4}\right)
$$

c. The PKN model: vertical fracture, vertical fracture, fracture width varies horizontally and vertically (Perkins and Kern 1961; Nordgren 1972).

$$
\bar{w}=0.40\left[\frac{\left.\mu q_{i}\left(1-v^{2}\right) x_{\mathrm{f}}\right)}{E}\right]^{\frac{1}{4}}\left(\frac{\pi}{4} \times 0.75\right)
$$




\section{Non-Darcy flow simulation}

At higher flow rates, in addition to the viscous force term represented by Darcy's equation, there is also an inertial force term due to convective accelerations of the fluid particles. Under these circumstances, the appropriate flow equation is the Forchheimer equation (1901). The first term depends on fluid viscosity " $\mu$ " and permeability " $k$ ", and the second term depends on fluid density " $\rho$ " and coefficient of inertial resistance " $\beta$ ". The importance of the second term can be analyzed using the concept of parameter non-Darcy function " $F_{\mathrm{ND}}$ " defined as:

$F_{\mathrm{ND}}=3.161 \times 10^{-12} \frac{\beta T \gamma_{\mathrm{g}}}{\mu_{\mathrm{g}} h_{\mathrm{p}}^{2} r_{\mathrm{w}}}$
Therefore, the non-Darcy flow is conventionally included in the inflow equation as an additional skin factor " $S_{\mathrm{d}}$ " as:

$S_{\mathrm{d}}=\frac{F_{\mathrm{ND}} k h}{1422 T} q_{\mathrm{g}}$

\section{Solving algorithm}

The algorithm of data processing is as Fig. 3:

The solution of the matrix by IMPES method is as Fig. 4:

In the constant bottomhole pressure constraint, phase's rate and saturations are updated with the help of new

Fig. 3 Simulation flowchart

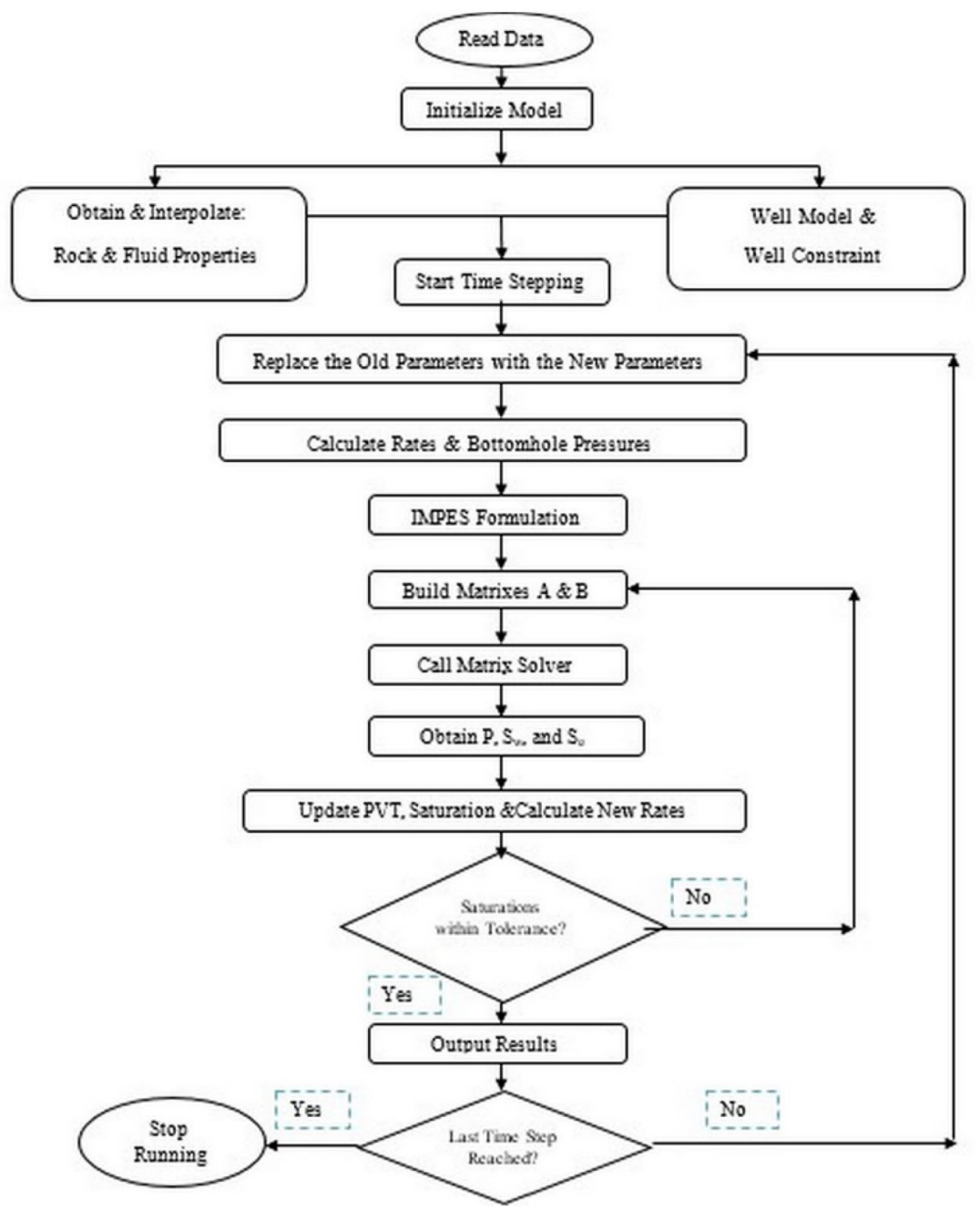


Fig. 4 IMPES method solution flowchart

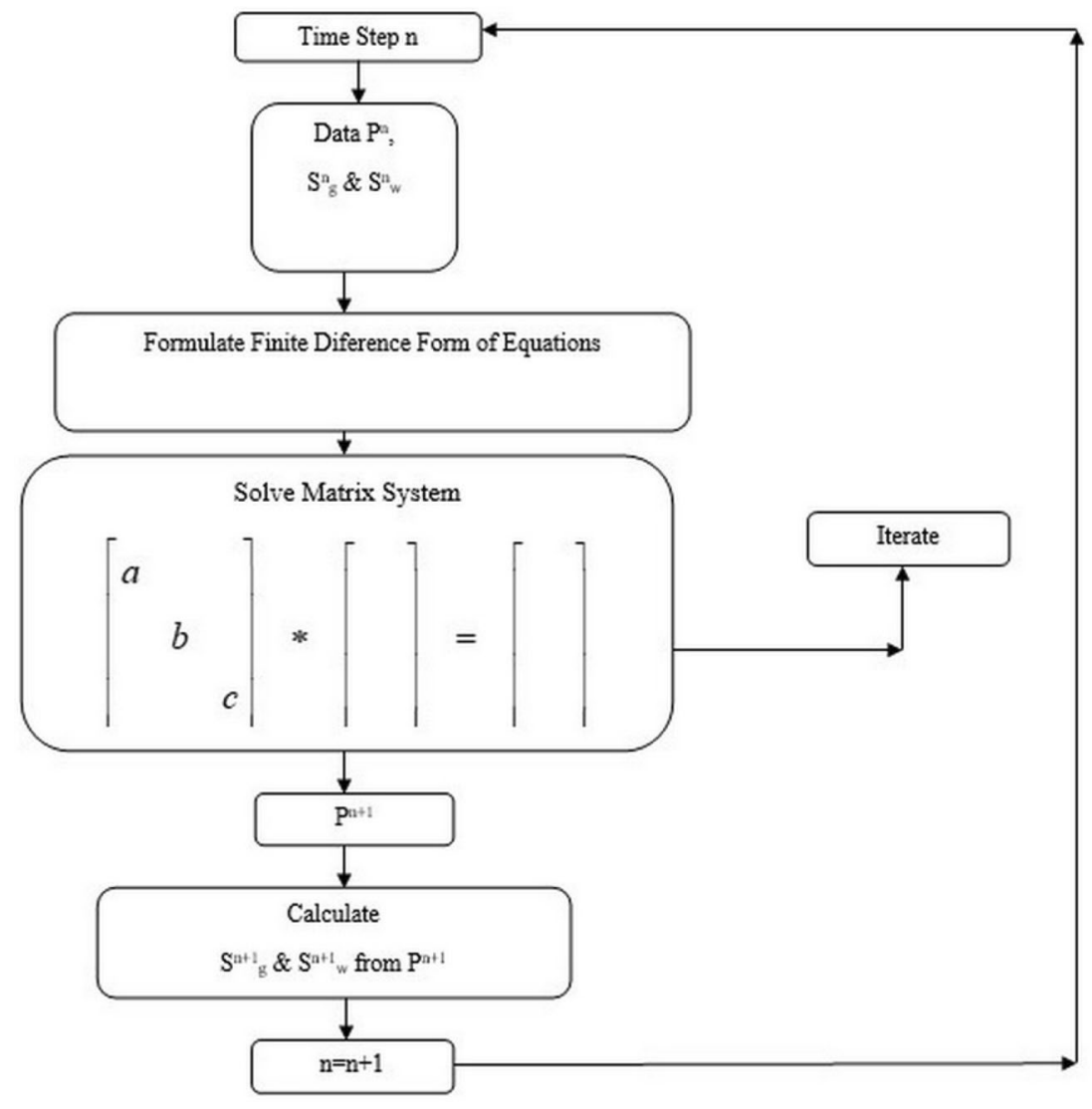

pressure. For the calculation of these rates, it is desired to calculate of productivity index, mobility, compressibility factor, and pore volume in the new time step.

In order to ensure the convergence of the IMPES method for each user's input data, it is necessary to have a cut or time step cut process. When new amounts of pressure were calculated and flow rates (or wellbore pressures) and saturations were updated subsequently, the main time loop passes from an inner loop of the time step cut to evaluate the decrease or increase in the time step. In this case, the time step is not just an input which can change the convergence. There is also another parameter in the input file called ncuts that the user can control the possible fastest convergence by changing it; ncuts provide the necessary amount of time step reduction to get the possible fastest convergence. The conditions for the time step cut procedure are shown in Fig. 5. In this algorithm, the counter is a variable initially set to zero.

After the time step is set, the simulator calculates cumulative production of gas and water.

Subsequently, for the constant flow rate constraint, if the calculated bottomhole pressure is less than the minimum bottomhole pressure "BHP" value in the input file, the 
Fig. 5 Time step cut flowchart

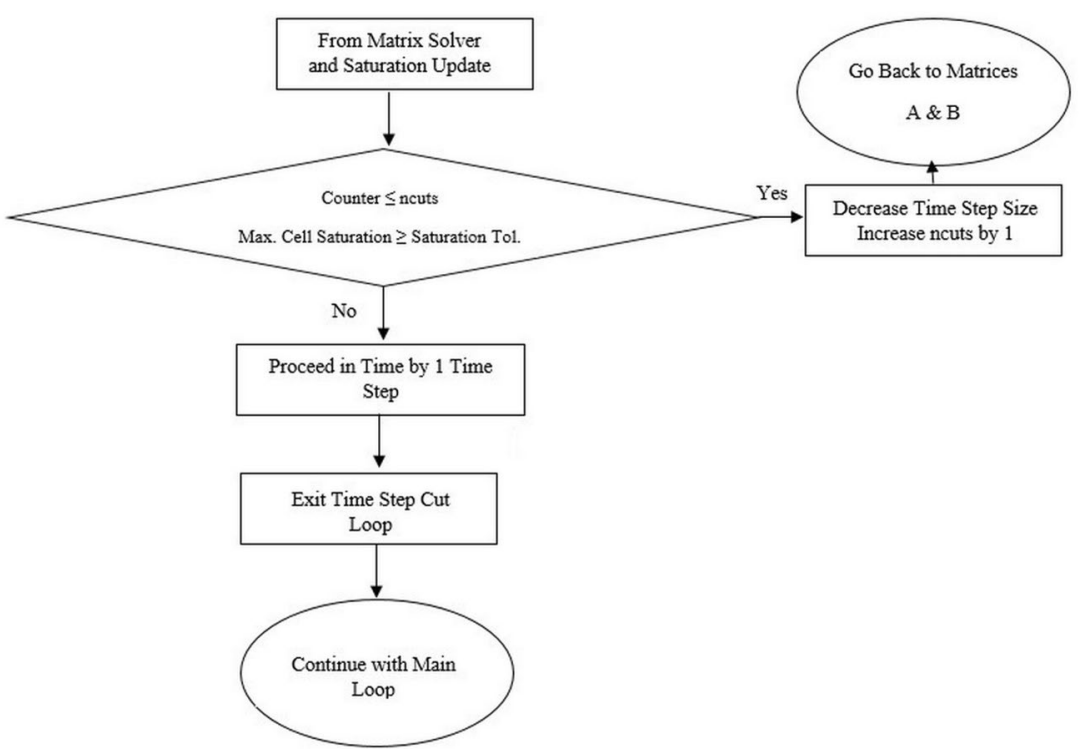

constraint of the well will vary from the constant flow rate to the constant bottomhole pressure.

\section{Results and discussion}

In order to verify the ability of the developed code, two case studies from dual porosity-dual permeability fractured dry gas reservoirs have been chosen. Both of these examples have been solved by the developed code and commercial software using Darcy's law equations.

In the first case study, the reservoir has been gridded by Cartesian coordinate and using the well's data from Tables 2 , $3,4,5,6,7$ and 8 . This reservoir has two production wells (multiple well model).

Table 2 Input data for gridding of case\#1

\begin{tabular}{llllll}
\hline NX (-) & NY (-) & NZ (-) & DX (ft) & DY (ft) & DZ (ft) \\
\hline 20 & 20 & 10 & $20 \times 600$ & $20 \times 600$ & $10 \times 50$ \\
\hline
\end{tabular}

Table 3 Reservoir properties of case \#1

\begin{tabular}{lllll}
\hline Properties & $\emptyset(-)$ & $k_{x}(\mathrm{md})$ & $k_{y}(\mathrm{md})$ & $k_{z}(\mathrm{md})$ \\
\hline Regions & & & & \\
Matrix & 0.3 & 20 & 20 & 10 \\
Fracture & 0.09 & 40 & 40 & 30 \\
\hline
\end{tabular}

Table 4 Initial conditions of case \#1

\begin{tabular}{lll}
\hline$P_{i}$ (Psia) & $S_{\mathrm{wi}}(-)$ & $\sigma(-)$ \\
\hline 3000 & 0.25 & 0.12
\end{tabular}

Table 5 Relative permeability and capillary pressure data according to saturation of case \#1

\begin{tabular}{llllll}
\hline & $S_{\mathrm{w}}(-)$ & $K_{\mathrm{rw}}(-)$ & $S_{\mathrm{g}}(-)$ & $K_{\mathrm{rg}}(-)$ & $P_{\mathrm{c}}$ (Psia) \\
\hline Matrix & 0.1 & 0 & 0 & 0 & 0 \\
& 0.4 & 0.056 & 0.3 & 0.04 & 0.2 \\
& 0.5 & 0.116 & 0.4 & 0.072 & 0.63 \\
& 1 & 1 & 0.85 & 0.532 & 4 \\
Fracture & 0.5 & 0.5 & 0.5 & 0.5 & 0 \\
& 1 & 1 & 0 & 0 & 0 \\
\hline
\end{tabular}

Table 6 Well input data of case $\# 1$

\begin{tabular}{lrrlll}
\hline$N_{\text {well }}$ & $X$ & $Y$ & $Z$ & Kind & Type \\
\hline 1 & 5 & 5 & 6 & $\mathrm{~V}$ & $\mathrm{P}$ \\
2 & 10 & 10 & 8 & $\mathrm{~V}$ & $\mathrm{P}$ \\
\hline
\end{tabular}

Figure 6 shows the comparison of the developed code results with the Eclipse software results for average reservoir pressure versus time for case \#1.

Figures 7, 8, 9 and 10 demonstrate the comparison of the developed code results with the software eclipse results for water flow rate and Pwf for well number 1 and gas flow rate and water flow rate for well number 2 of case \#1.

As it is shown in Figs. 6, 7, 8, 9 and 10, there is a good agreement between the developed code results and Eclipse simulation results.

In case \#2, the reservoir has been gridded by Cartesian coordinate using the data from Tables 9, 10, 11 and 12. This 
Table 7 Well input data of case \#1

\begin{tabular}{lllllll}
\hline$N_{\text {well }}$ & $Q_{\mathrm{w}}(\mathrm{Mscf})$ & $Q_{\mathrm{g}}(\mathrm{Mscf})$ & $P_{\mathrm{wf}}($ Psia $)$ & $R_{\mathrm{w}}(\mathrm{ft})$ & $S(-)$ & $P_{\mathrm{BH}, \min }$ (Psia) \\
\hline 1 & 0 & 1000 & 0 & 0.3 & 0 & 1000 \\
2 & 0 & 0 & 2500 & 0.35 & 0 & 1000 \\
\hline
\end{tabular}

Table 8 PVT data

\begin{tabular}{lccllll}
\hline Pressure & Gas compressibility & Water compressibility & Gas viscosity & Water viscosity & Shrinkage factor & Water formation factor \\
\hline$P(\mathrm{Psi})$ & $C_{\mathrm{g}}{ }^{*} 1.0 \mathrm{e}-003(1 / \mathrm{psi})$ & $C_{\mathrm{w}}{ }^{*} 1.0 \mathrm{e}-005(1 / \mathrm{psi})$ & $\mu_{\mathrm{g}}(\mathrm{Cp})$ & $\mu_{\mathrm{w}}(\mathrm{Cp})$ & $\mathrm{Eg}=1 / \mathrm{Bg}(\mathrm{scf} / \mathrm{rcf})$ & $\mathrm{Bw}(\mathrm{rcf} / \mathrm{scf})$ \\
3000 & 0.5157 & 0.2995 & 0.0315 & 0.9752 & 294.1761 & 0.9908 \\
2974.47 & 0.5189 & 0.2997 & 0.0313 & 0.9752 & 293.0350 & 0.9909 \\
2951.87 & 0.5217 & 0.3000 & 0.0311 & 0.9752 & 292.0124 & 0.9910 \\
2927.21 & 0.5248 & 0.3002 & 0.0310 & 0.975 & 290.8830 & 0.9910 \\
2911.2 & 0.5268 & 0.3004 & 0.0308 & 0.9752 & 290.1418 & 0.9911 \\
2884.31 & 0.5302 & 0.3007 & 0.0306 & 0.9752 & 288.8829 & 0.9912 \\
2859.43 & 0.5333 & 0.3010 & 0.0305 & 0.9752 & 287.7018 & 0.9912 \\
2836.12 & 0.5363 & 0.3012 & 0.0303 & 0.9752 & 286.5807 & 0.9913 \\
2810.45 & 0.5396 & 0.3015 & 0.0301 & 0.9752 & 285.3294 & 0.9914 \\
2785.2 & 0.5428 & 0.3017 & 0.0299 & 0.9752 & 284.0811 & 0.9915 \\
2749.32 & 0.5474 & 0.3021 & 0.0297 & 0.9752 & 282.2763 & 0.9916 \\
\hline
\end{tabular}

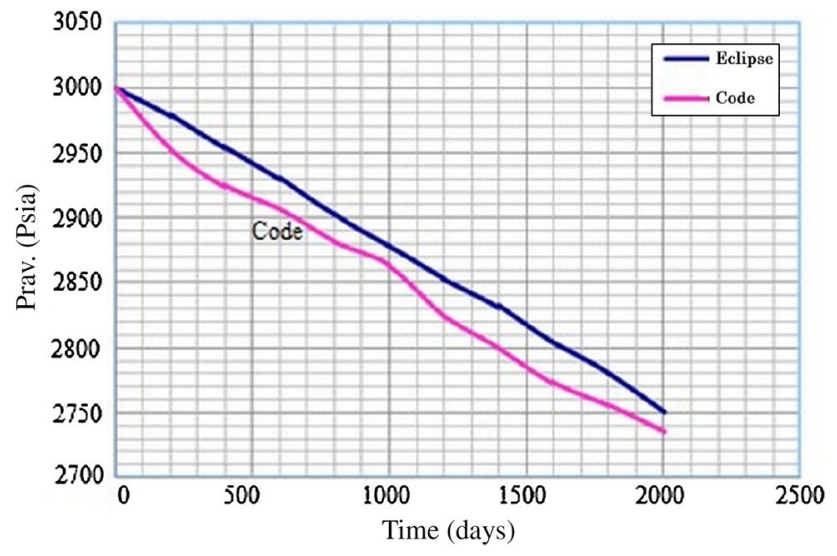

Fig. 6 Average reservoir pressure versus time of case \#1

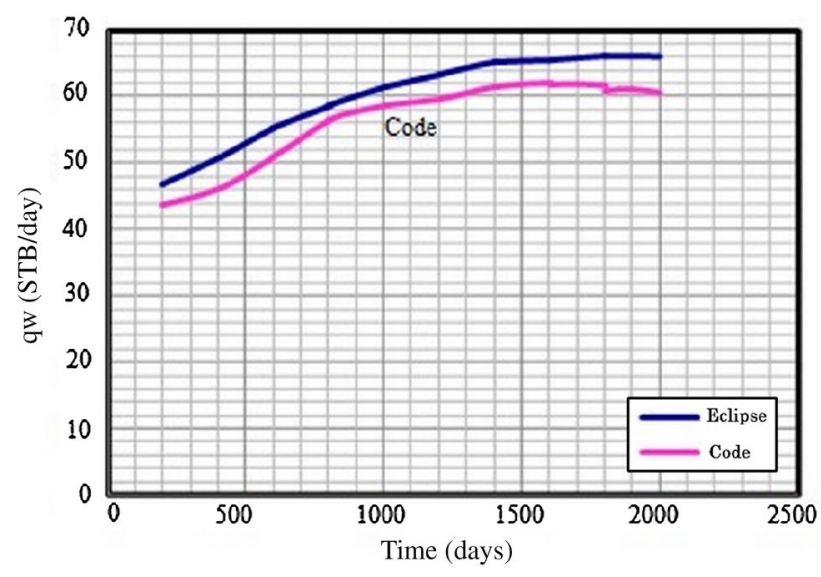

Fig. 7 Water flow rate versus time for well No. 1 of case \#1

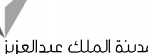

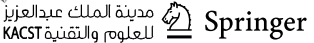

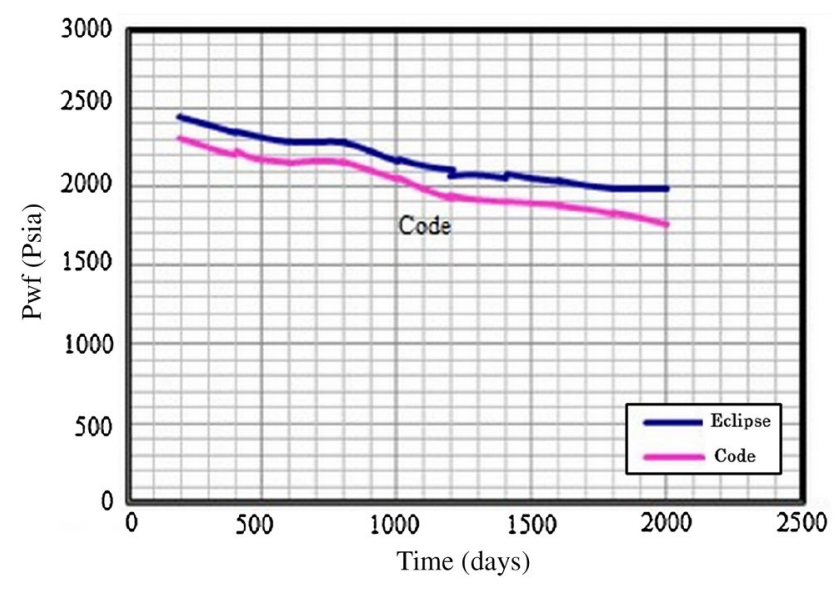

Fig. 8 Pwf versus time for well No. 1 of case \#1

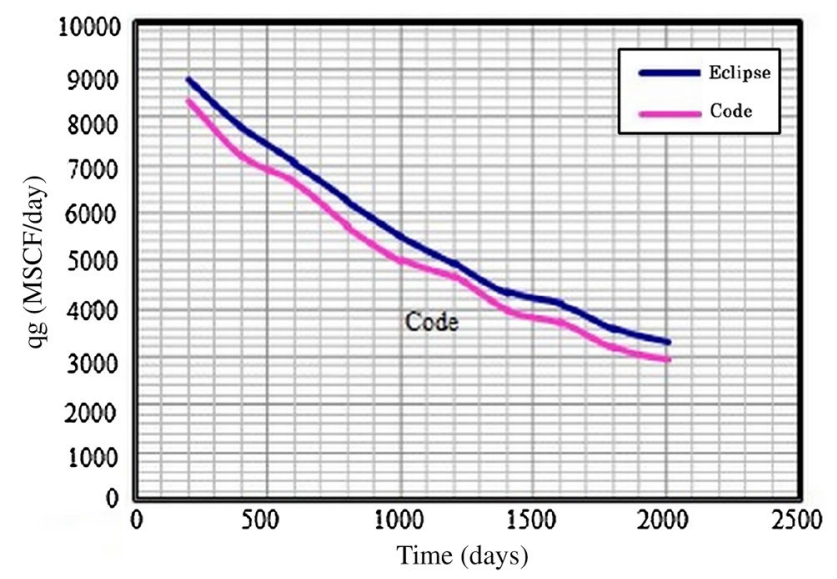

Fig. 9 Gas flow rate versus time for well No. 2 of case \#1 


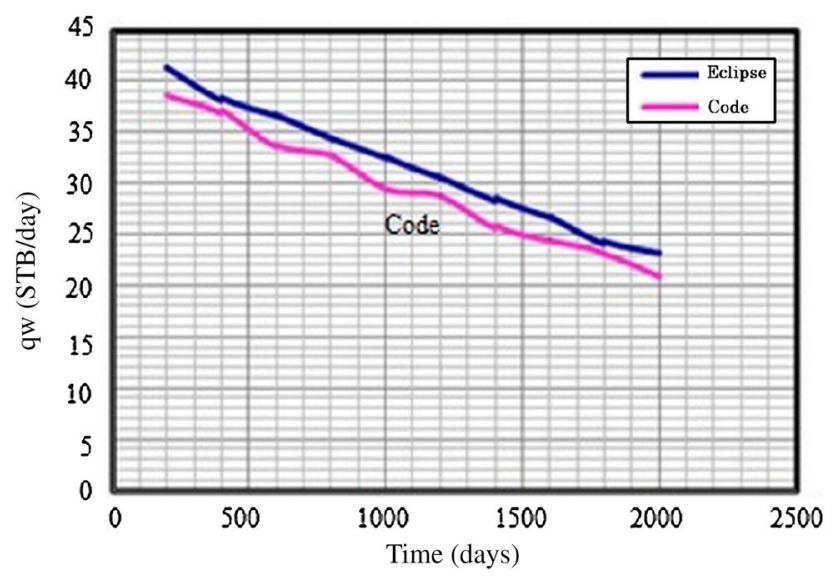

Fig. 10 Water flow rate versus time for well No. 2 of case \#1

Table 9 Reservoir properties of case \#2

\begin{tabular}{lllll}
\hline Properties regions & $\begin{array}{l}\text { Porosity } \\
\emptyset\end{array}$ & $\begin{array}{l}x \text {-Perme- } \\
\text { ability } k_{x} \\
(-)\end{array}$ & $\begin{array}{l}y \text {-Perme- } \\
\text { ability } k_{y} \\
(\mathrm{md})\end{array}$ & $\begin{array}{l}z \text {-Perme- } \\
\text { ability } k_{z} \\
(\mathrm{md})\end{array}$ \\
\hline Matrix & 0.35 & 30 & 30 & 10 \\
Fracture & 0.1 & 60 & 60 & 40 \\
\hline
\end{tabular}

Table 10 Initial conditions of case\#2

\begin{tabular}{lll}
\hline$P_{i}$ (Psia) & Swi (-) & $\sigma(-)$ \\
\hline 4260 & 0.3 & 0.19 \\
\hline
\end{tabular}

Table 11 Well input data of case \#2

\begin{tabular}{lrrrll}
\hline$N_{\text {well }}$ & $X$ & $Y$ & $Z$ & Kind & Type \\
\hline 1 & 2 & 5 & 4 & V & I \\
2 & 15 & 12 & 3 & V & P \\
\hline
\end{tabular}

reservoir has two production and injection wells (multiple well model). The wells' properties are shown in the following tables.

The relative permeability and capillary pressure data are the same as case \#1.

Figure 11 shows the comparison of the developed code results with the Eclipse software results for average reservoir pressure versus time for case \#2.

Figure 12 shows the comparison of the developed code results with the Eclipse software results for gas flow rate versus time for case \#2.

The reservoir average pressure has a descending trend until 200 days. Since the reservoirs are gas type, the reservoir pressure has a slow descending trend.
In the first case study, the well \#1 has been modeled as non-Darcy flow model $\left(F_{\mathrm{ND}}=0.046\right)$ and hydraulically fractured well $(\mathrm{HFW})$ model $\left(F_{\mathrm{CD}}=0.192\right)$.

Figure 13 shows the comparison of the Darcy with the non-Darcy flow model using the developed code for case \#1 (well \#1).

Figure 14 shows the comparison of the HFW with the nonHFW model using the developed code for case \#1 (well \#1).

As it is shown in Figs. 13 and 14, the pressure drop in the wellbore increases in the non-Darcy flow model and decreases in the HFW model in comparison of the Darcy flow model and non-HFW model, respectively.

Finally, Tables 13 and 14 show the error percent "Err\%" of each calculated parameter by FDGRS simulator based on the same calculated parameter by Eclipse simulator with the help of the following equation.

Err $\%_{\mathrm{pa}}=\frac{\left|\overline{p a}_{\text {Eclipse }}-\overline{p a}_{\mathrm{FDGRS}}\right|}{\overline{p a}_{\text {Eclipse }}}$

\section{Conclusions}

In this study, a simulation code has been developed to predict the fractured dry gas reservoir's behavior that contains the PVT and gridding boxes separately with the high flexibility due to the new correlations and EOS. Moreover, this code is able to grid the reservoir applying three coordinate (Cartesian, cylindrical, and cylindrical-Cartesian). Based on the simulation results, it is shown that by applying the cylindrical gridding around the well and Cartesian gridding in other regions of formation, the error of simulation decreases. However, this simulator is able to simulate the hydraulically fractured well reservoirs too. Also, the developed code applies three models for simulation: single porosity-single permeability, dual porosity-single permeability, and dual permeability-dual porosity. The simulation results show that the single porosity model can describe the reservoir as a non-fractured reservoir unlike that, if the simulation applies the more complex models such as the dual permeability-dual porosity, the error of simulation increases. However, the governing equations of fracture and matrix also consider both Darcy and non-Darcy effect (skin). The simulation results show that considering the non-Darcy effect around the well because of high gas velocity around the well, give more acceptable results. It is noted that the pressure drop in the wellbore increases in the non-Darcy flow model
Table 12 Well input data of case \#2

\begin{tabular}{llllllc}
\hline$N_{\text {well }}$ & $Q_{\mathrm{w}}(\mathrm{Mscf})$ & $Q_{\mathrm{g}}(\mathrm{Mscf})$ & $P_{\mathrm{wf}}($ Psia $)$ & $R_{\mathrm{w}}(\mathrm{ft})$ & $S(-)$ & $P_{\mathrm{BH}, \min }($ Psia $)$ \\
\hline 1 & 50 & 100 & 0 & 0.3 & 0 & 1500 \\
2 & 0 & 100 & 0 & 0.35 & 0 & 900 \\
\hline
\end{tabular}


Fig. 11 Average reservoir pressure versus time of case \#2

Fig. 12 Gas flow rate versus time of case \#2
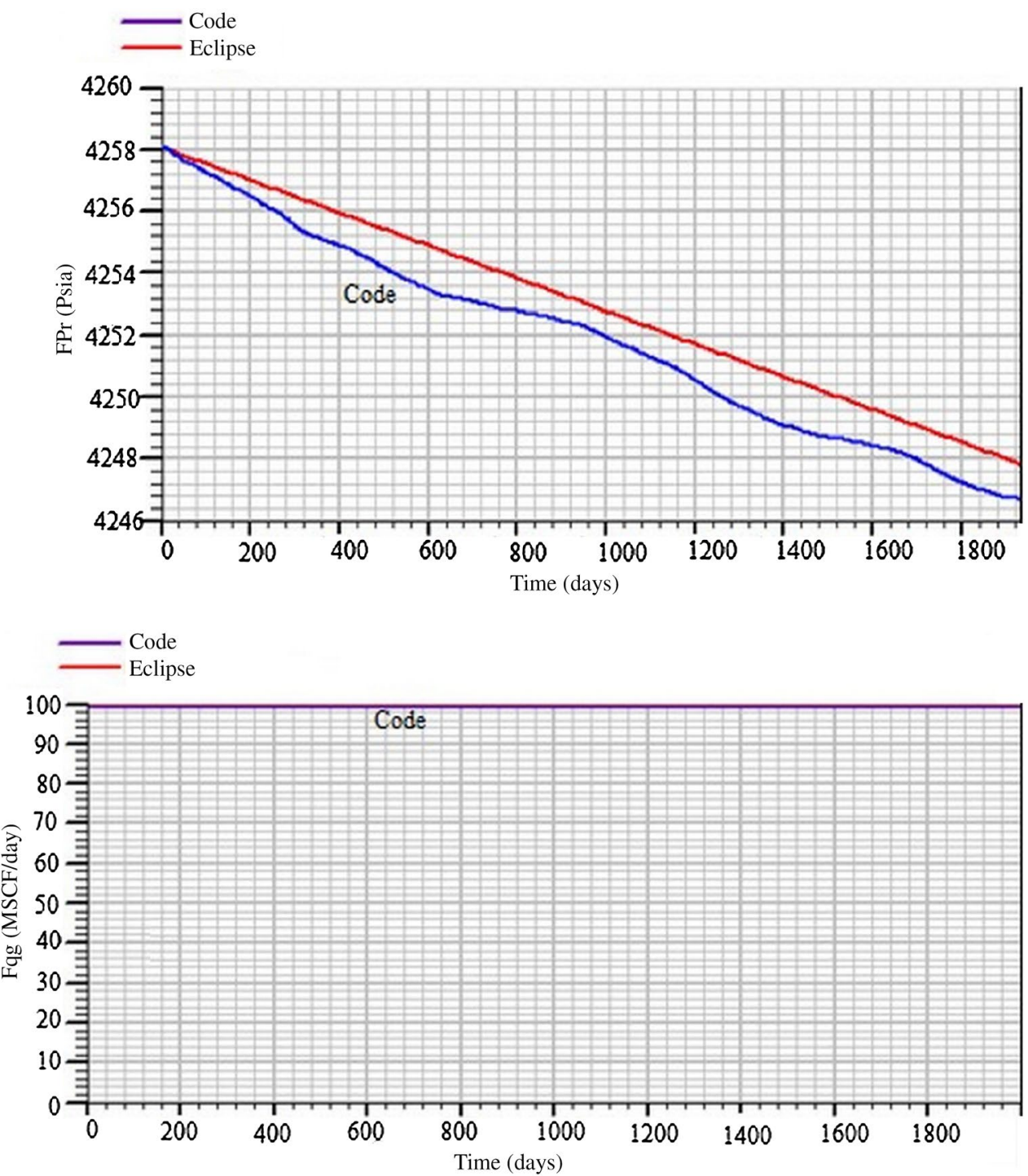

and decreases in the HFW model in comparison of the Darcy flow model and non-HFW model, respectively.

For the dry gas flow in the reservoir (in absence of condensates or oil), the fluid flow has been controlled by fluid compressibility and the viscous force. So, the gravity force is negligible.

This developed software is compatible with other commercial software such as Eclipse and CMG that is able to make outputs (such as pressure) at any given specific radius and in each time interval as numerical and/or graphical output in so little run time, so we can see pressure changes at any radius from wellbore radius to reservoir radius that has very low error with the other simulator results.

Fig. 13 Comparison of the Darcy with the non-Darcy flow model 

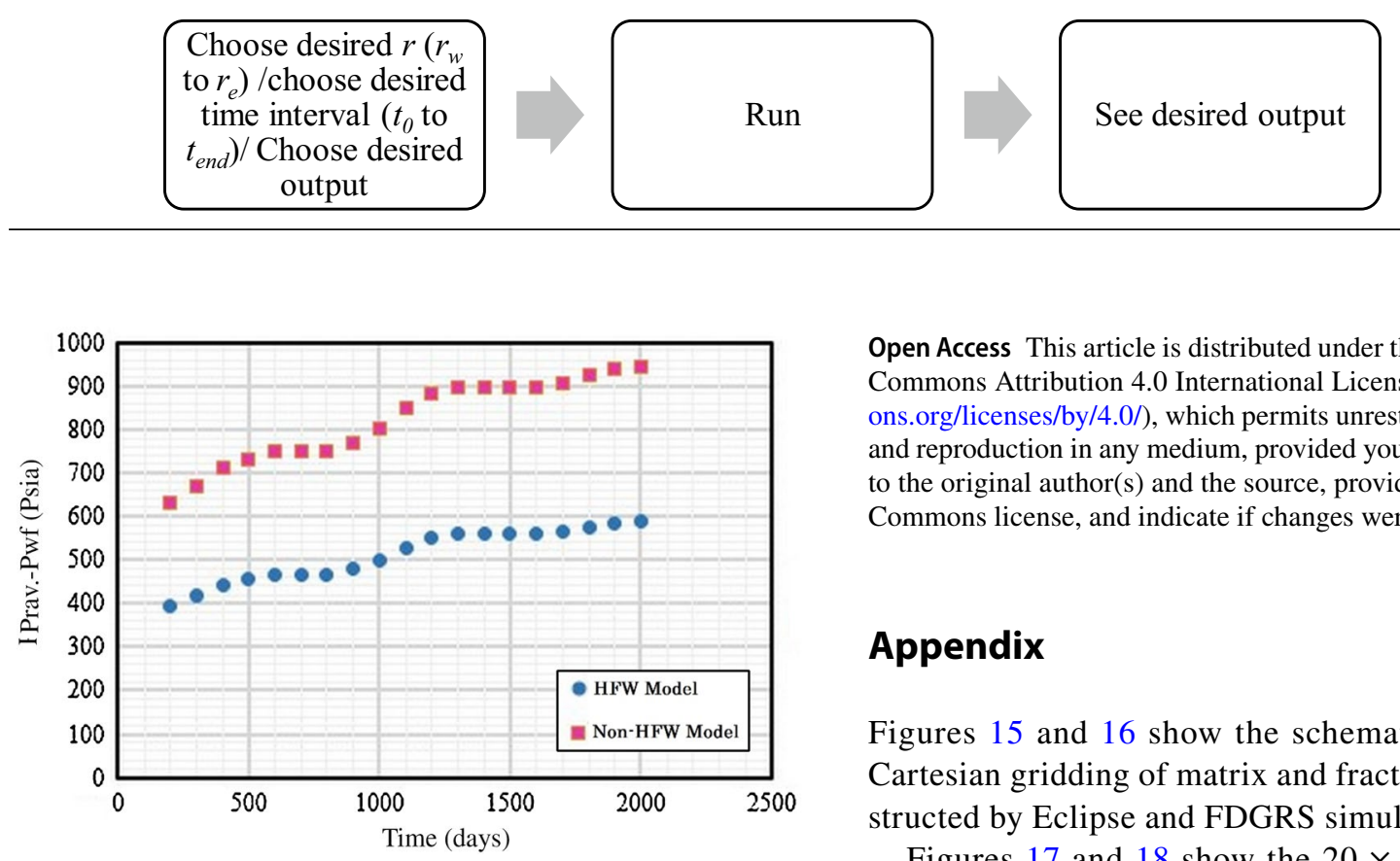

Fig. 14 Comparison of the HFW with the non-HFW model

Table 13 Error percent of calculated parameters of case\#1 by FDGRS simulator

\begin{tabular}{lllll}
\hline Parameter & $P_{\text {rav. }}$ & $P_{\text {wf }}$ & $q_{\mathrm{w}}$ & $q_{\mathrm{g}}$ \\
\hline Err\% & 0.86 & 7.09 & 5.32 & 7.90 \\
\hline
\end{tabular}

Table 14 Error percent of calculated parameters of case\#2 by FDGRS simulator

\begin{tabular}{lll}
\hline $\mathrm{Pa}$ & $\mathrm{FP}_{\mathrm{r}}$ & $\mathrm{Fq}_{\mathrm{g}}$ \\
\hline Err\% & 0.01 & 0.00 \\
\hline
\end{tabular}

Open Access This article is distributed under the terms of the Creative Commons Attribution 4.0 International License (http://creativecomm ons.org/licenses/by/4.0/), which permits unrestricted use, distribution, and reproduction in any medium, provided you give appropriate credit to the original author(s) and the source, provide a link to the Creative Commons license, and indicate if changes were made.

\section{Appendix}

Figures 15 and 16 show the schematic of $20 \times 20 \times 4$ Cartesian gridding of matrix and fracture system are constructed by Eclipse and FDGRS simulator, respectively.

Figures 17 and 18 show the $20 \times 20 \times 10$ " $(x, y, z)$ " Cartesian gridding systems of case \#1 and case \#2, respectively, are constructed by FDGRS simulator in this study.

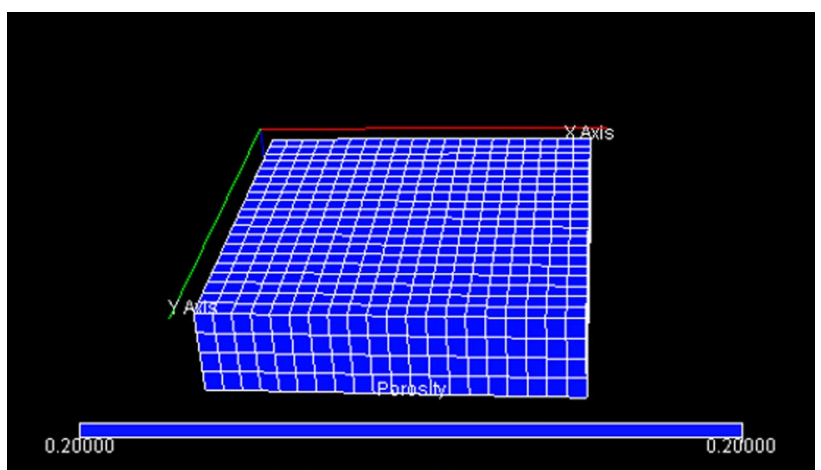

Fig. 15 Schematic of Cartesian gridding in Eclipse simulator

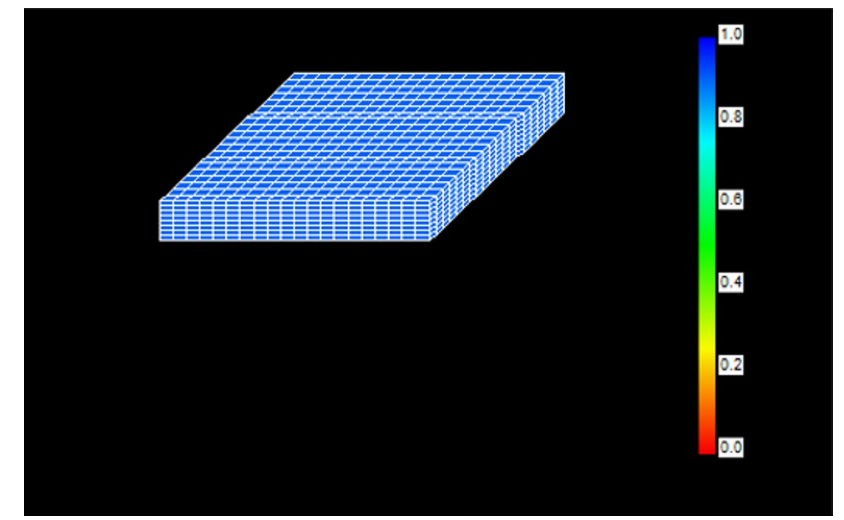

Fig. 16 Schematic of Cartesian gridding in FDGRS simulator
Choose a desired specific radius $\left(r_{\mathrm{w}}\right.$ to $\left.r_{\mathrm{e}}\right) \rightarrow$ Choose a desired specific output $\rightarrow$ Run $\rightarrow$ See output in each time interval $\left(t_{0}\right.$ to $\left.t_{\text {end }}\right)$.

Finally, its results are very same to the real condition, because of its flexibility which makes us consider effects and parameters of fracture and matrix at any direction $(X$, $Y$, and $Z$ direction).

Additionally, in comparison with others simulators, it is very low costly.

Acknowledgements The acknowledgements are for the Shiraz University for supporting this research. 

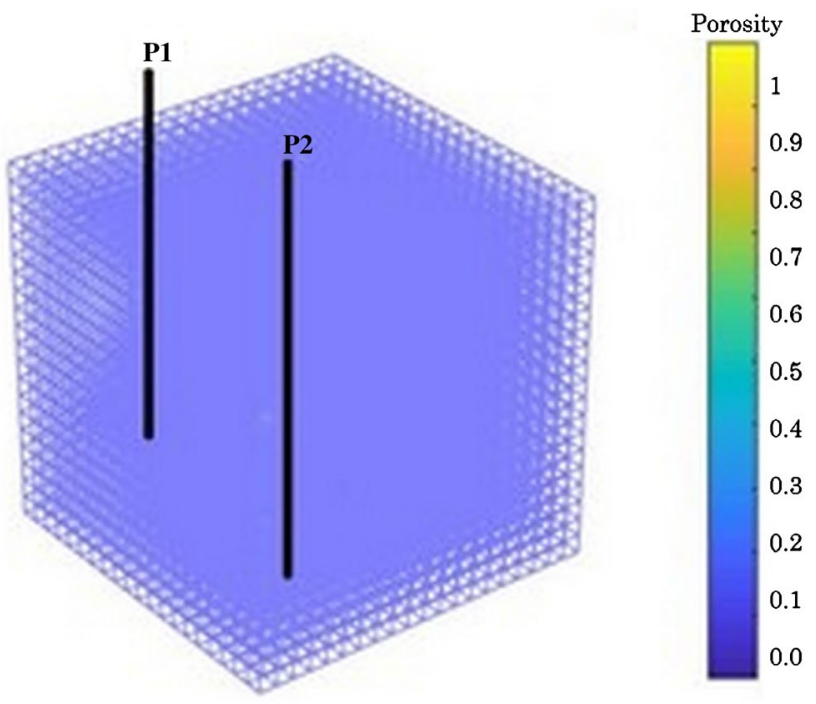

Fig. 17 Cartesian gridding system of case \#1
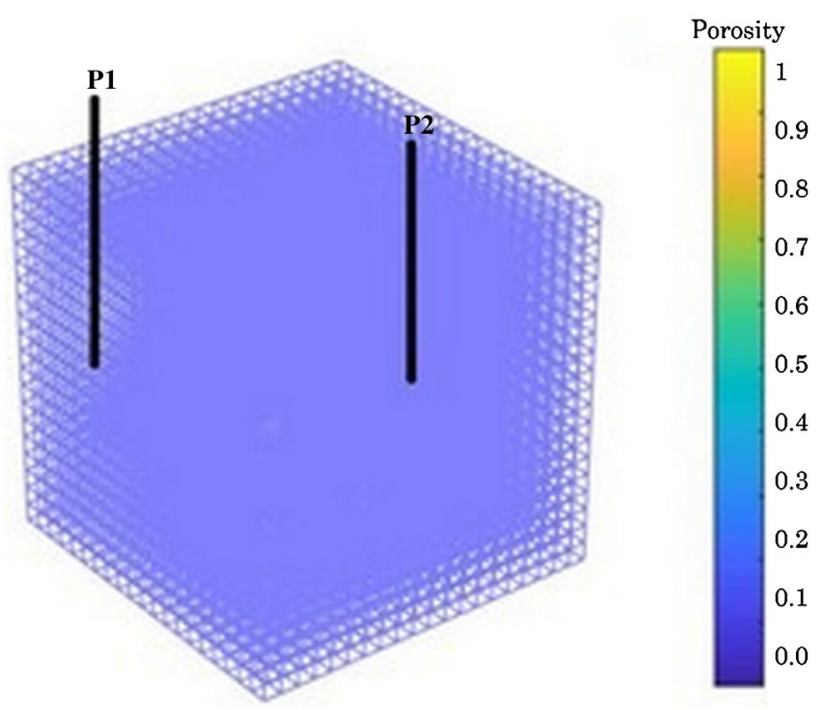

Fig. 18 Cartesian gridding system of case \#2

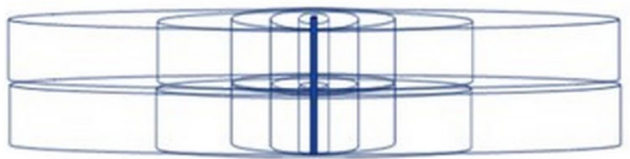

Fig. 19 Cylindrical gridding system of well \#1, case \#1
Table 15 Cylindrical gridding system characteristics of well\#1, case\#1

\begin{tabular}{lrrllllll}
\hline Ii & \multicolumn{1}{l}{$R_{\mathrm{C}}$} & \multicolumn{1}{l}{$R_{\mathrm{w}}$} & \multicolumn{1}{l}{$R_{\mathrm{e}}$} & $R_{\mathrm{C}} / R_{\mathrm{w}}$ & $R_{\mathrm{E}} / R_{\mathrm{e}}$ & $R_{\mathrm{w}} / R_{\mathrm{W}}$ & $R_{\mathrm{e}} / R_{\mathrm{C}}$ & $R_{\mathrm{e}} / R_{\mathrm{w}}$ \\
\hline 1 & 0.58 & $0.30^{\mathrm{a}}$ & 1.37 & 1.95 & 1.95 & - & 2.35 & 4.57 \\
2 & 2.67 & 1.37 & 6.27 & 1.95 & 1.95 & 2.35 & 2.35 & 4.57 \\
3 & 12.21 & 6.27 & 28.69 & 1.95 & 1.95 & 2.35 & 2.35 & 4.57 \\
4 & 55.82 & 28.69 & 131.20 & 1.95 & 1.95 & 2.35 & 2.35 & 4.57 \\
5 & 255.27 & 131.20 & $600^{\mathrm{b}}$ & 1.95 & - & 2.35 & 2.35 & 4.57 \\
\hline
\end{tabular}

${ }^{\mathrm{a}} R_{1-1 / 2}=r_{\mathrm{w}}$

${ }^{\mathrm{b}} R_{5+1 / 2}=\left.r_{\mathrm{e}}\right|_{\text {well grid }}$

$\left(R_{i i}=R_{\mathrm{C}}, R_{i i-1 / 2}=R_{\mathrm{w}}, R_{i i+1 / 2}=R_{\mathrm{e}}, R_{i i-1}=R_{\mathrm{W}}, R_{i i+1}=R_{\mathrm{E}}\right)$

Figure 19 also shows the $5 \times 1 \times 1$ " $(r, \theta, z)$ " cylindrical gridding system of well \#1, case \#1.

Table 15 additionally shows the $5 \times 1 \times 1$ cylindrical gridding system characteristics of well \#1, case \#1.

\section{References}

Abdassah D, Ershaghi I (1986) Triple-porosity systems for representing naturally fractured reservoirs. SPEFE 1:113-127

Afidick D, Kaczorowski NJ, Bette S (1994) Production performance of a retrograde gas reservoir: a case study of the Arun field. In: SPE, $\mathrm{p} 73$

Agarwal RG, Carter RD, Pollock CB (1979) Evaluation and prediction of performance of low-permeability gas wells stimulated by massive hydraulic fracturing. J Petrol Technol 267:362-372

Al-Fattah SM, Startzman RA (1999) Analysis of worldwide natural gas production. In: SPE, p 57463

Ansah J (1996) Production rate and cumulative production models for advanced decline curve analysis of gas reservoirs. Ph.D. Dissertation, Texas A\&M University

Asar H, Handy L (1988) Influence of interfacial tension on gas/oil relative permeability in a gas-condensate system. In: SPE, p 11740

Aziz K, Settari A (1999) Petroleum reservoir simulation. Elsevier, New York

Barrenblatt G, Zheltov I, Kochina I (1960) Basic concepts in the theory of seepage of homogeneous liquids in fissured rocks. Appl Math Mech 24:852-864

Bonyadi M (2006) Simulation of gas condensate well productivity by using pseudo pressure method. M.Sc. Thesis, Shiraz University

Calvin CC, Dalton RL (1990) Reservoir simulation. SPE Monograph Series, Monograph 13, Richardson, Huston Texas

Cather M, Guo B, Schechter DS, Banik A (1998) An integrated geology-reservoir description and modeling of the naturally fractured spraberry trend area reservoirs. PETSOC 1:32-98

Chang EY, Lo TS, ARCO Oil and Gas Co (1991) A numerical dispersion-free method for modeling the gas cycling process. In: SPE, p 22940

Cinco-Ley H (1981) Transient pressure analysis for fractured wells. J Petrol Technol 33:1749-1766

Cinco-Ley H, Samaniego-V F, Kucuck F (1985) The pressure behavior for naturally fractured reservoirs with multiple block size. In: SPE, p 14168 
Coats KH, Thomas LK, Pierson RG (1998) Compositional and black oil reservoir simulation. In: SPE, p 50990

Hatzignatiou DG, Reynolds AC (1996) Determination of effective or relative permeability curves from well tests. SPE J 1:69-82

Dreier J, Ozkan E, Kazemi H (2004) New analytical pressure-transient models to detect and characterize reservoirs with multiple fracture systems. In: SPE, p 92039

Eilerts CK, Sumner EF, Potts NL (1965) Integration of partial differential equation for transient radial flow of gas condensate fluids in porous structures. SPE J 5:141

Ejraei Bakyani A, Sahebi H, Ghiasi MM, Mirjordavi N, Esmaeilzadeh F, Lee M, Bahadori A (2016a) Prediction of $\mathrm{CO}_{2}$-oil molecular diffusion using adaptive neuro-fuzzy inference system and particle swarm optimization technique. Fuel 181:178-187

Ejraei Bakyani A, Heidari S, Esmaeilzadeh F (2016b) Linear regression to predict two-phase relative permeability of fracture network. In: 3rd international conference on research in engineering, science, and technology, RSTCONF03_149

Esmaeilzadeh F, Roshanfekr M (2006) A new cubic equation of state for reservoir fluids. Fluid Phase Equilib 239:83

Fevang O, Whitson CH (1999) Gas condensate relative permeability for well calculations. In: SPE, p 56476

Geertsma J, De Klerk F (1969) A rapid method of predicting width and extent of hydraulically induced fractures. J Petrol Technol 21:1571-1581

Hallam R, Kin ML (2003) Performance of Trinidad gas reservoirs (Cassia, Immortelle, Flamboyant, Mahogany, Amherstia and Teak). In: SPE, p 81010

Henderson GD, Danesh A, Al-Kharusi B, Tehrani D (2000) Generating reliable gas condensate relative permeability data used to develop a correlation with capillary number. J Petrol Sci Eng 25:79-91

Hoier L, Cheng N, Whitson CH (2004) Miscible gas injection in under saturated gas-oil systems. In: SPE, p 90379

Jones JR, Raghavan R (1988) Interpretation of flowing well response in gas-condensate wells (includes associated papers 19014 and 19216). In: SPE, p 14204

Jones TA, Wooten SO, Kaluza TJ (1988) single-phase flow through natural fractures. In: SPE, p 18175

Kazemi H (1969) Pressure transient analysis of naturally fractured reservoirs with uniform fracture disturbtion. SPE J 9:372-463

Khristianovich SA, zheltov YP (1955) Formation of vertical fractures by means of highly viscous liquid. In: Proceedings of the SPE fourth world petroleum congress held in Rome, Section II, p 579

Kniazeff VY, Naville SA (1965) Two-phase flow of volatile hydrocarbon. SPE J 37:234

Malachowski MA, Yanosik JL, Saldana MA, Batten AH (1995) Simulation of well productivity losses due to near well condensate accumulation in field scale simulations. In: SPE, p 30715
Mott R (2000) Measurements and simulation of inertial and high capillary number flow phenomena in gas-condensate relative permeability. In: SPE, p 62932

Mott R (2003) Engineering calculation of gas condensate well productivity. In: SPE, p 86298

Muskat M (1949) Physical principles of oil production. MC Graw-Hill Book Company Inc., New York

Nordgren RP (1972) Propagation of a vertical hydraulic fracture. SPEJ 12:306-314

O'Dell HG, Miller RN (1967) Successfully cycling a low permeability high-yield gas condensate reservoir. JPT 41:240

Peaceman DW (1982) Interpretation of well-block pressures in numerical reservoir simulation with non-square grid blocks and anisotropic permeability. In: SPE, p 10528

Penuela G, Civan F, Hughes RG, Wiggins ML (2002) Time-dependent shape factors for inter-porosity flow in naturally fractured gascondensate reservoirs. In: SPE, p 75524

Perkins TK, Kern LR (1961) Widths of hydraulic fractures. J Petrol Technol 13:937-949

Putra E, Schechter DS (2003) Numerical modeling notes. NFR Group at Texas A\&M University, College Station

Rice JC (1997) Effect of fracture spacing distribution on pressure transient response in naturally fractured reservoirs. Petrol Sci Eng 20:31-47

Roebuck F, Henderson E (1969) The compositional reservoir simulator; the two dimensional model. In: SPE, p 2235

Saeidi A, Handy L (1974) Flow and phase behavior of gas condensate and volatile oils in porous media. In: SPE, p 4891

Seto CJ, Jessen K, Orr Jr FM (2003) Compositional streamline simulation of field scale condensate vaporization by gas injection. In: SPE, p 79690

Shane KF, Hattingh BD (2009) A finite element approach for modelling single-phase compressible flow in dual porosity systems. J Petrol Sci Eng 69:1-24

Staggs HM, Herbeck EF (1971) Reservoir simulation models—an engineering overview. J Petrol Technol 23:1428-1436

Valko P, Oligney RE, Economides MJ (1997) High permeability fracturing of gas wells. Gas TIPS 3:31-40

Warren JE, Root PJ (1963) The behavior of naturally fractured reservoirs. SPE J 3:245-255

Wattenbarger RA (2002) Reservoir simulation, class notes for PETE 603. Texas A\&M University, College Station

Publisher's Note Springer Nature remains neutral with regard to jurisdictional claims in published maps and institutional affiliations. 